\title{
Exercise Preconditioning and Neuroprotection: A Review of Mechanisms
}

\author{
Ali Samadi* \\ Department of Physical Education and Sport Science, Faculty of Humanities, Shahed University, Tehran, Iran.
}

\section{A BSTRACT}

Introduction: Cerebrovascular accident or stroke is the first cause of acquired disability and the third leading cause of mortality in adults. It is known that exercise modifies risk factors such as hypertension, lipid profile, diabetes that may play an important role in the prevention of cerebrovascular accidents. However, recent findings suggest that besides adjusting the risk factors of stroke, exercise may be helpful in inducing endogenous neuroprotection and neuronal survival in ischemia-reperfusion condition which is the main mechanism of ischemic stroke. The effect of previous exercises in protecting neurons against ischemic injury and inducing neuronal resistance known as exercise preconditioning, which is a relatively new field of research on the effects of exercise on the brain. Although the exact mechanisms of neuroprotection induced by exercise preconditioning have yet to be known, previous studies have shown that exercise preconditioning may be helpful through several mechanisms, such as strengthening blood-brain barrier, inducing cerebral angiogenesis and arteriogenesis, improving cerebral metabolism and decreasing neuronal metabolic disturbances following ischemic injury, upregulation of neurotrophins expression, as well as reducing inflammation, apoptosis, and oxidative stress. Conclusion: It seems that exercise preconditioning in people predisposed to brain ischemic injuries or in people with history of mild ischemic injury may help in reducing the primary damage and improve the neurological outcomes

\section{Key words:}

1. Exercise

2. Stroke

3. Ischemia after ischemia-reperfusion injury. However, more research is needed to develop exercise protocols with appropriate time, intensity, and type to induce the optimal neuroprotection.

* Corresponding Author: Ali Samadi

E-mail: a.samadi@Shahed.ac.ir 


\title{
ييش آمادهسازى با فعاليت ورزشى و حفاظت عصبى: مرورى بر مكانيسمها
}

\author{
على صمدى"
}

كروه تربيت بدنى و علوم ورزشى، دانشكده علوم انسانى، دانشكاه شاهد، تهران، ايران.

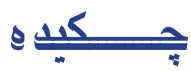

مقدمه: حوادث عروق مغزى يا سكتهٔ مغزى نخستين عامل ناتوانى و سومين علت مرى و مير در افراد

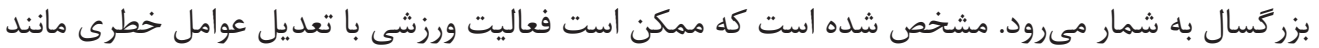

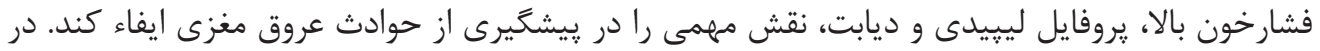

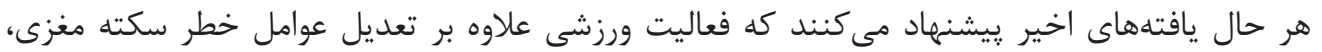

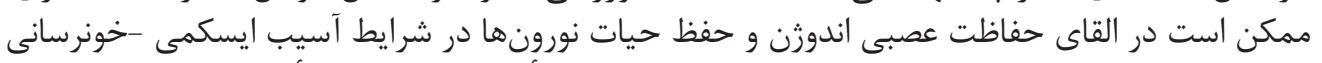

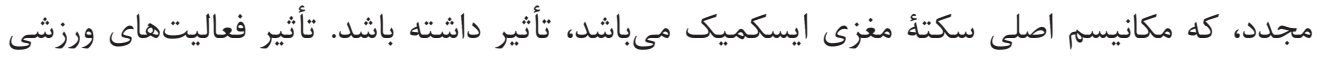

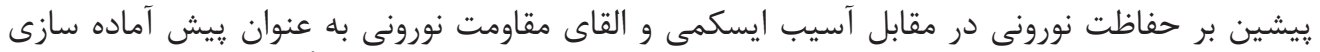

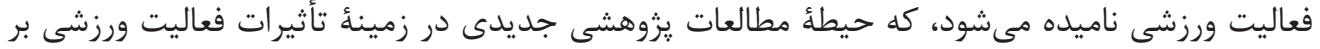

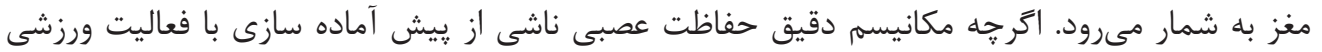

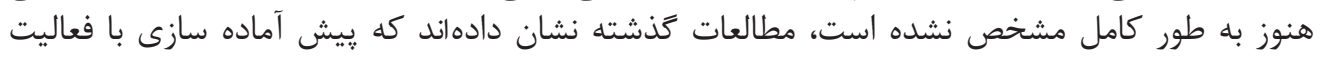

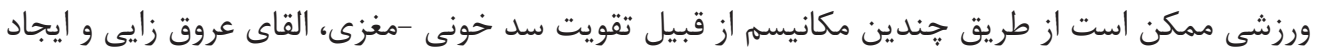

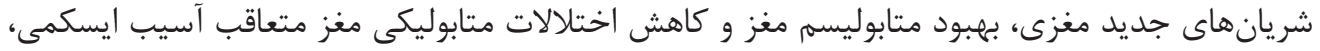

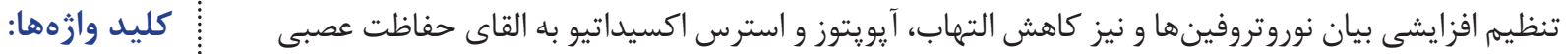

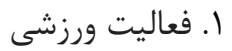

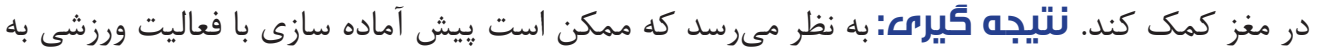

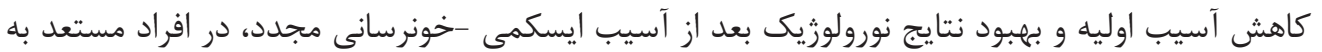

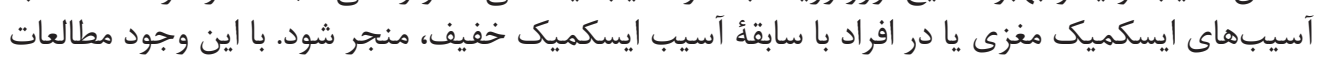

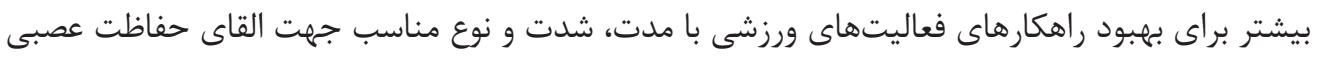
بهينه مورد نياز است.

" نويسنده مسئول: على صمدى : آدرس الكترونيكى: a.samadi@Shahed.ac.ir 


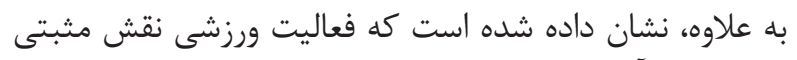

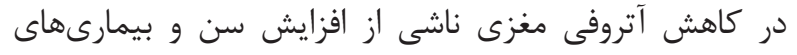

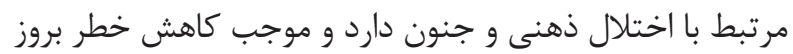

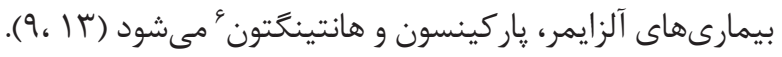
هر קند مكانيسم دقيق حفاظت عصبى ناشى از يِيش آماده سازى با بان

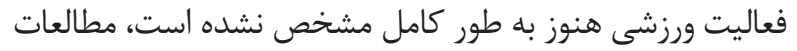

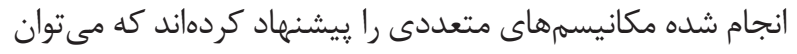

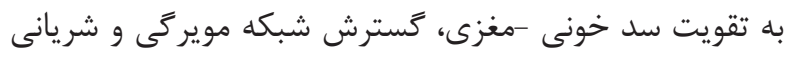

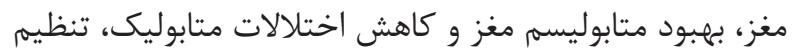

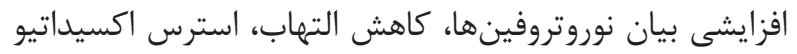

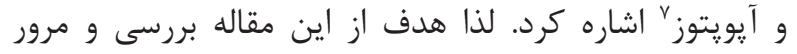

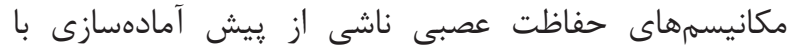

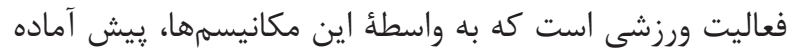

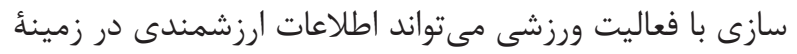

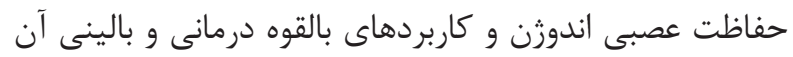

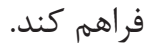

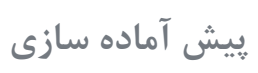

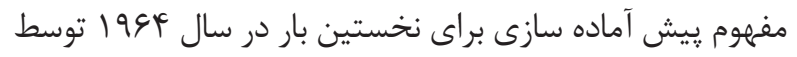

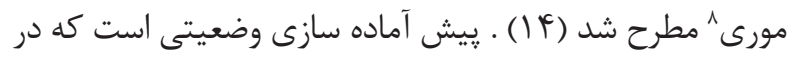

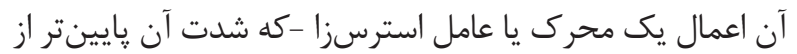

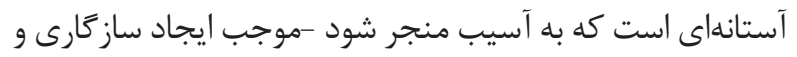

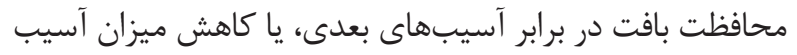

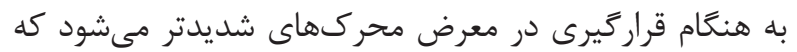

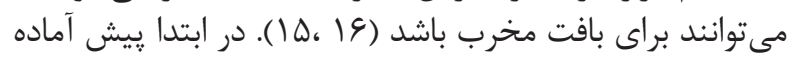

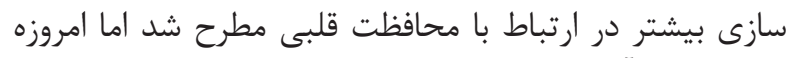

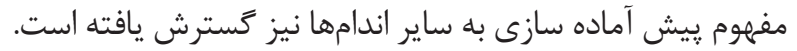

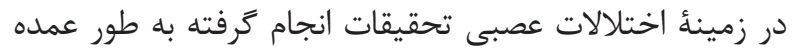

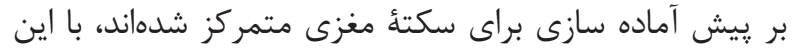

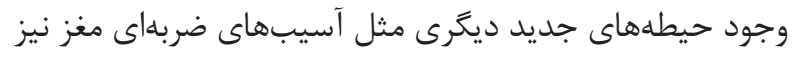

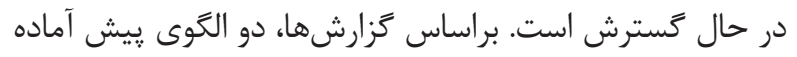

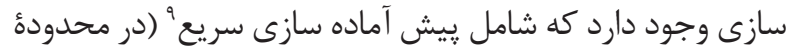

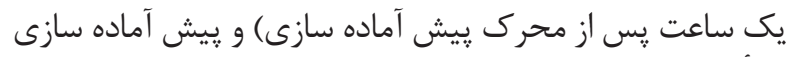
با تأخير 'مى مباشد.

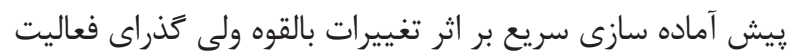

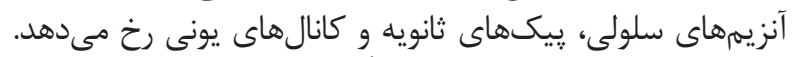

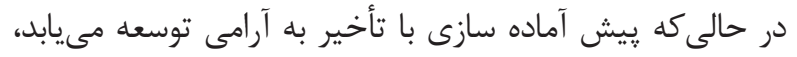

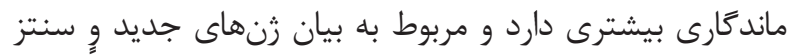

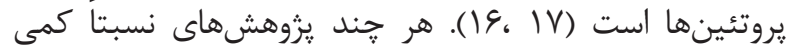

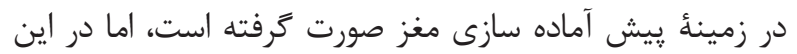

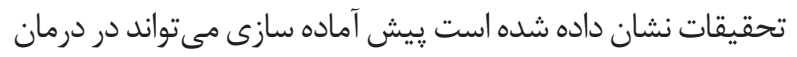

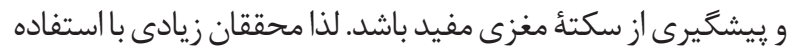

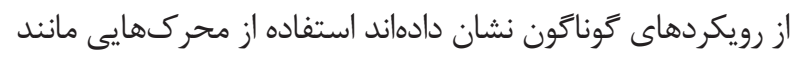

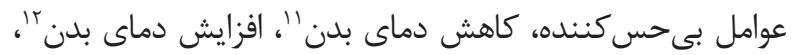

\footnotetext{
${ }^{1}$ Neuroprotection

${ }^{2}$ Ischemia-Reperfusion injury

${ }^{3}$ Infarct volume

${ }^{4}$ Neurologic recovery

${ }^{5}$ Preconditioning

${ }^{6}$ Huntington's disease
}

حادثئ عروق مغزى يا سكتئُ مغزى، يك اختلال عصبى حاد است

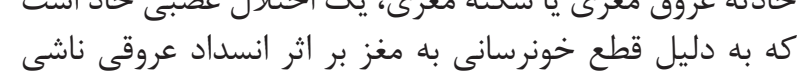

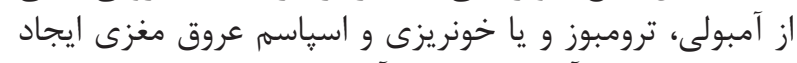

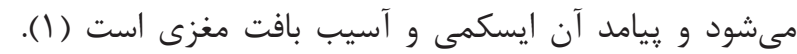

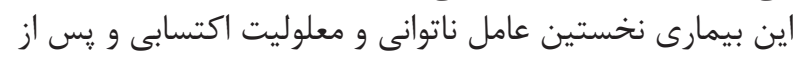

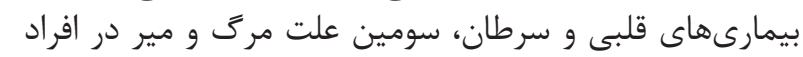

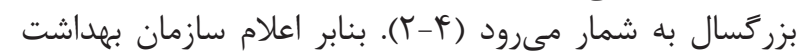

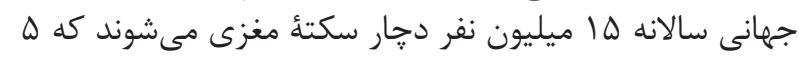

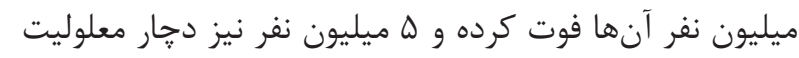

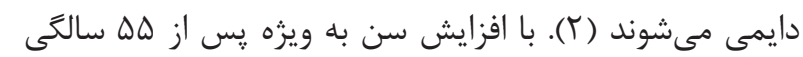

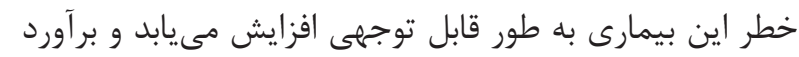

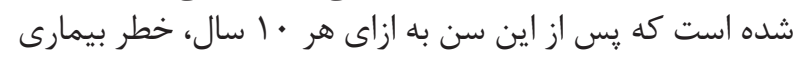

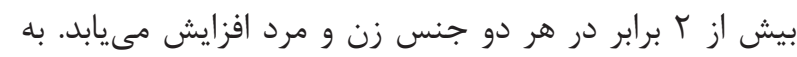

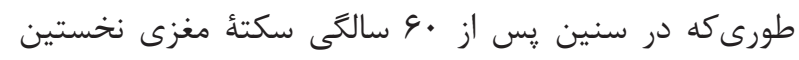

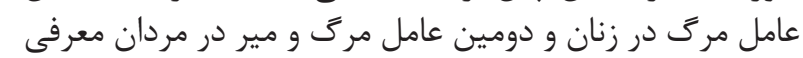

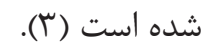

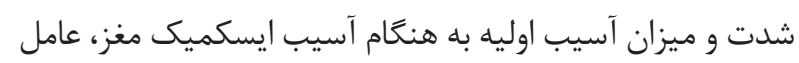

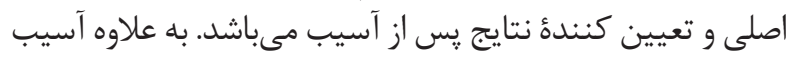

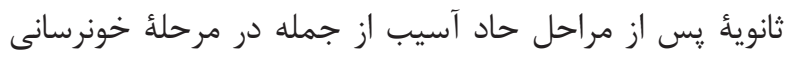

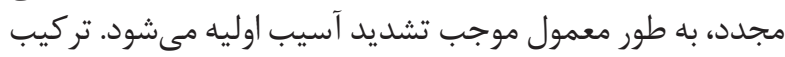

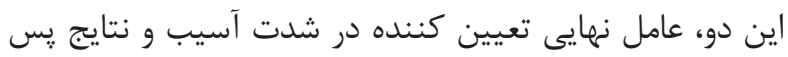

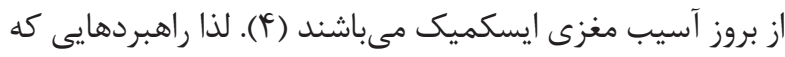

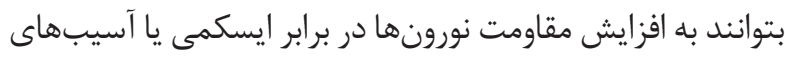

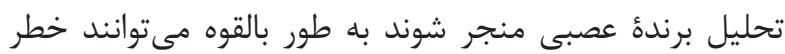
حوادث و اختلالات عصبى را كاهش دهن دهند.

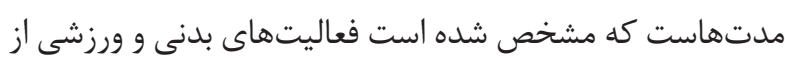

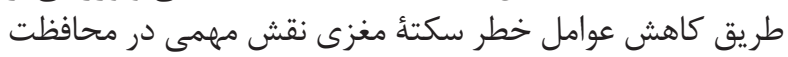

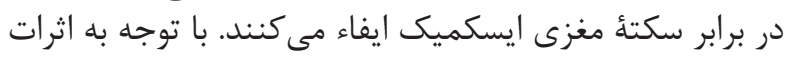

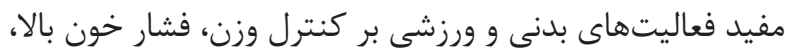

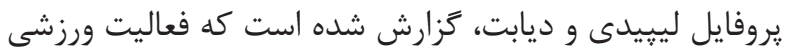

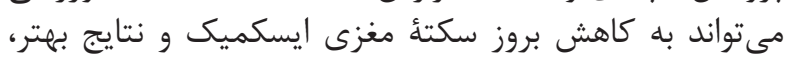

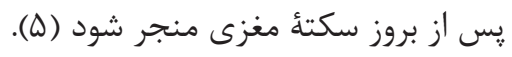

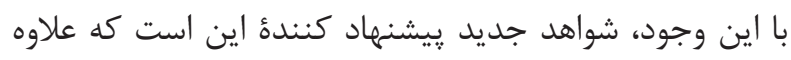

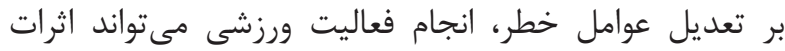

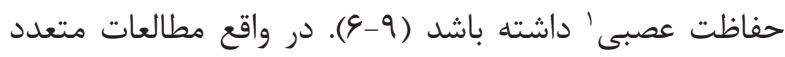

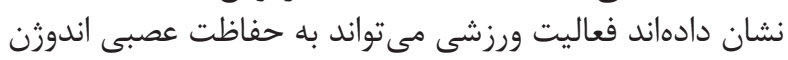

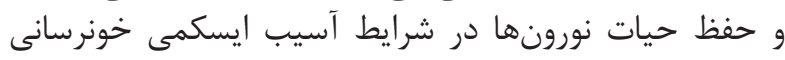

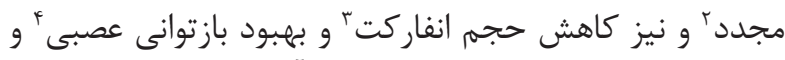

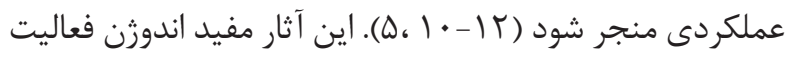

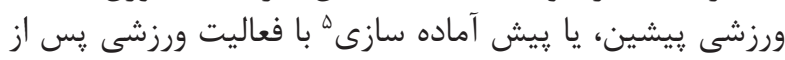

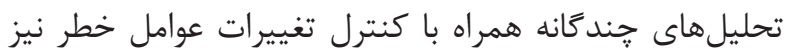
مشاهده شده است.

\footnotetext{
${ }^{7}$ Apoptosis

${ }^{8}$ Murry

${ }^{9}$ Rapid preconditioning

${ }^{10}$ Delayed preconditioning

${ }^{11}$ Hypothermia

${ }^{12}$ Hyperthermia
} 
زمانى كه اين سد بر اثر عاملى مانند سكتهٔ مغزى يا آسيب

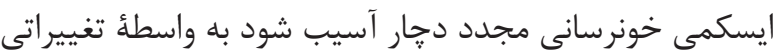

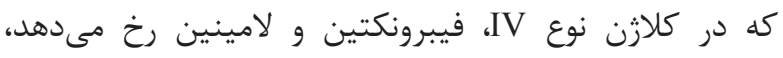

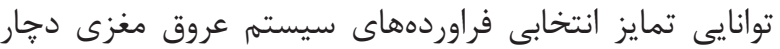

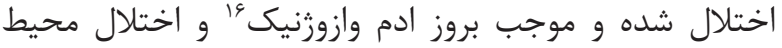

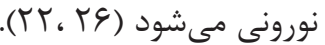

از اين رو افزايش مقاومت سد خونى -مغزى به طور بالقوه مي تواند

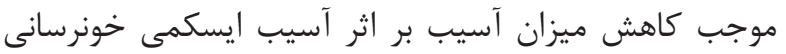

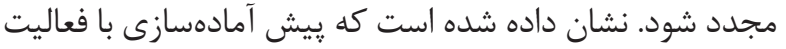

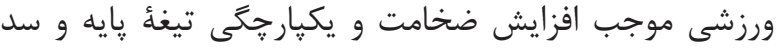

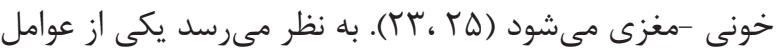

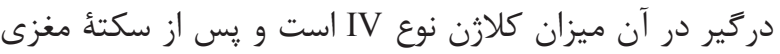

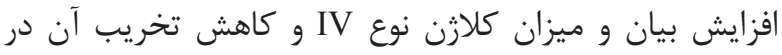

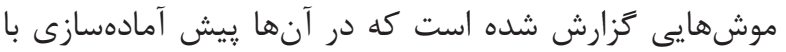

فعاليت ورزشى انجام شده بود (V).

علاوه بر كلازن نوع IV و ساير يروتئينهاى ساختارى تيغهُ يايه،

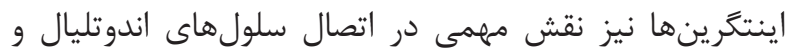

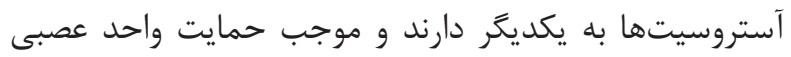

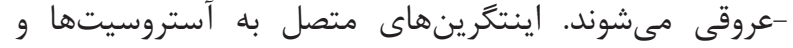

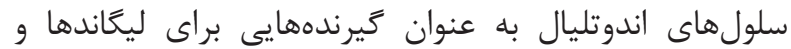

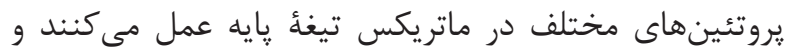

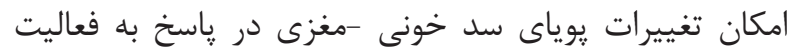

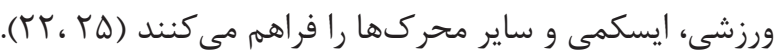

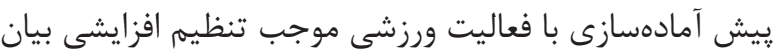

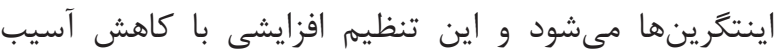

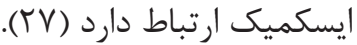

كزارش شده است يِيش آمادهسازى با فعاليت ورزشى از راه

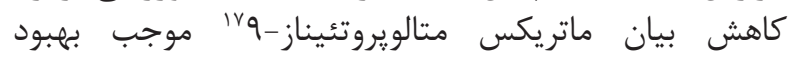

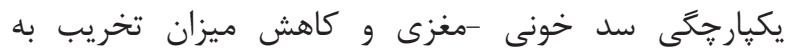

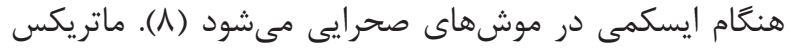

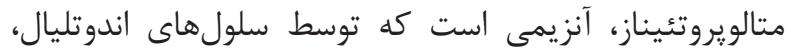

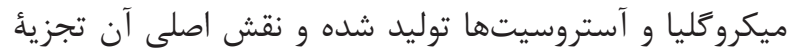

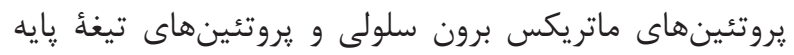

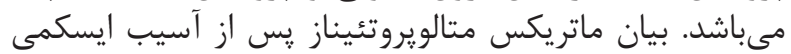

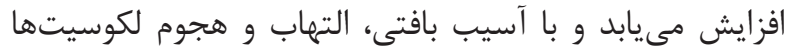

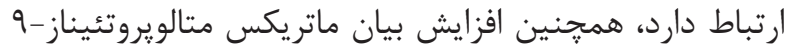
از طريق افزايش نفوذيذيرى سد خوني ارنى -مغزى به به ادم و آسيب

عصبى منجر مىشود (Y^).

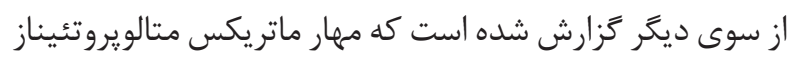

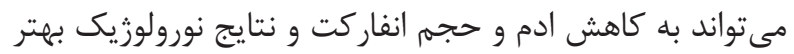

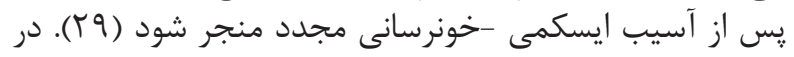

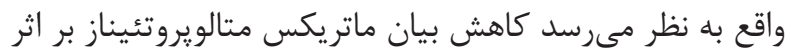

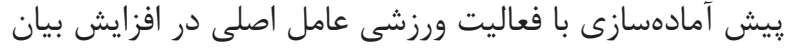

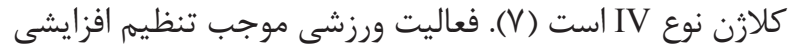

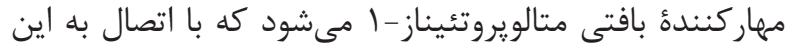

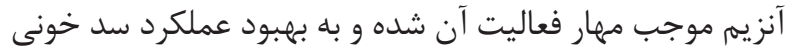

${ }^{13}$ Neurovascular unit

${ }^{14}$ Astrocytes

${ }^{15}$ Basal lamina

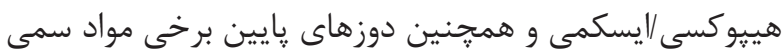

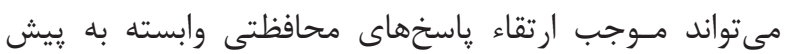
آماده سازى شود (1) (1).

موضوعات اخلاقى و يِيامدهاى احتمالى اين رويكردها، استفاده

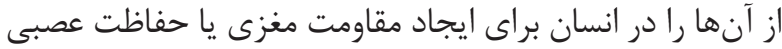

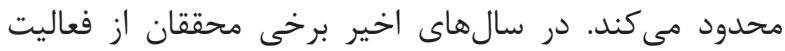

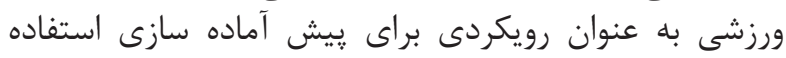

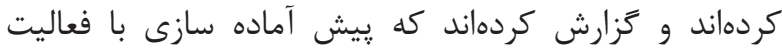

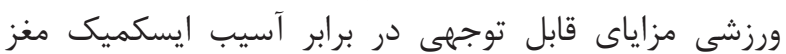

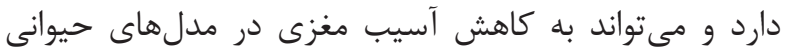

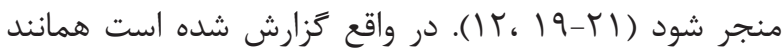

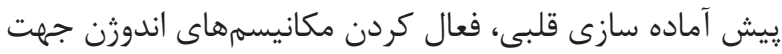

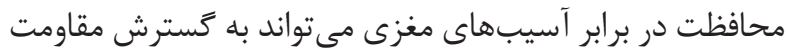

مغزى منجر شود (1) مل (1).

مطالعات از اهميت فعاليت ورزشى به عنوان مداخلهاى كاربردى

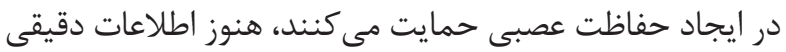

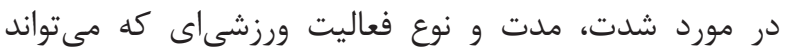

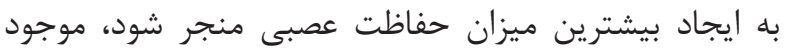

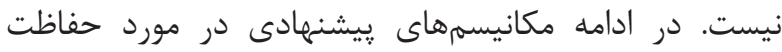
عصبى اندوزن ناشى از فعاليت ورزشى در برابر آسيب آسيب ايسكمى دئى -خونرسانى مجدد بحث مى اندون ناشي فعاليت

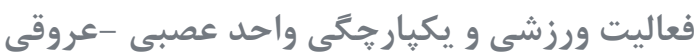

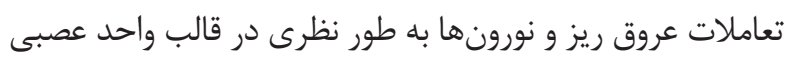

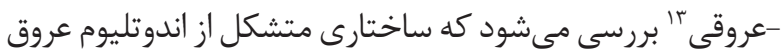

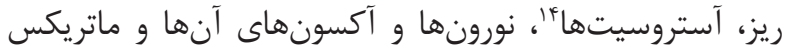

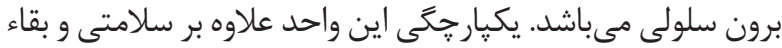

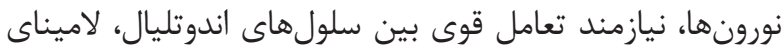

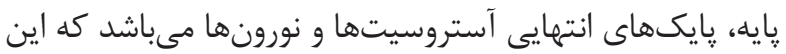

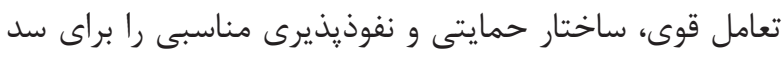

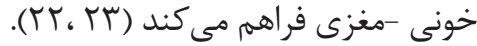

اين سد واسط تنظيمى بين جريان خون محيطى و دستخاه

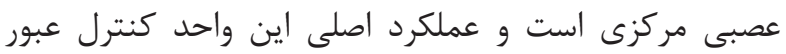

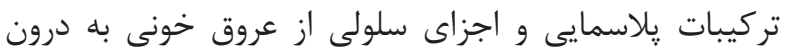

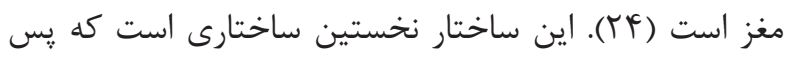

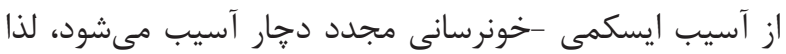

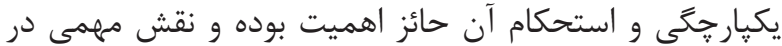
حفاظت عصبى در شرايط آسيب ايسكمى دارد (هانَ).

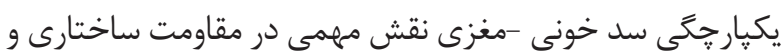

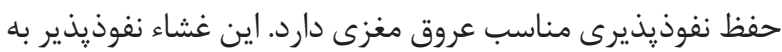

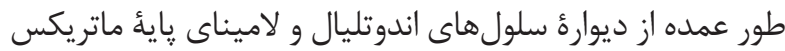

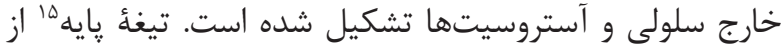

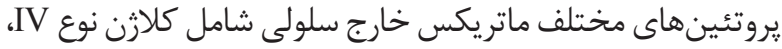

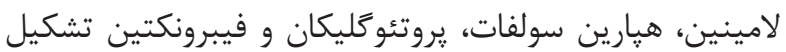

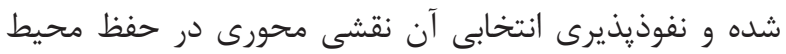

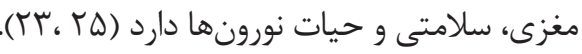

${ }^{17}$ Matrix metalloproteinase 9 (MMP-9) 


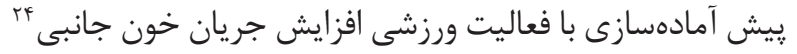

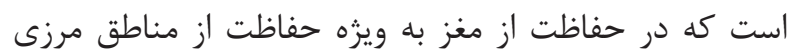

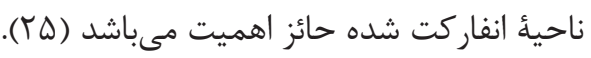
به نظر مى رسد مكانيسم تغييرات ساختارى ايجاد شده در عروق تُون

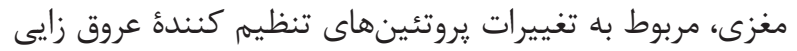

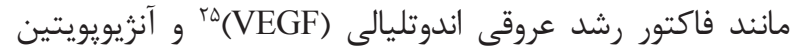

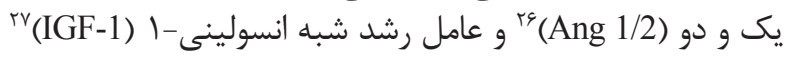

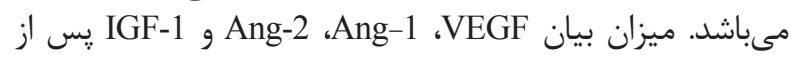

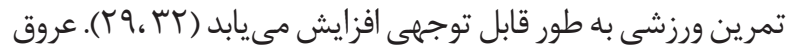

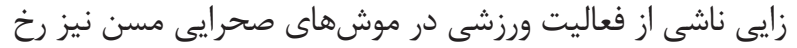

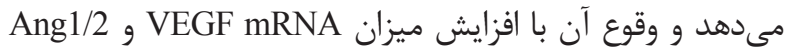

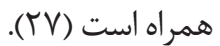

هر جند بيشتر تكثير در سيستم عروقى -عصبى در طول دوران

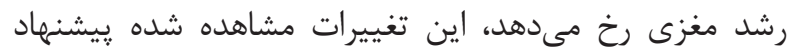

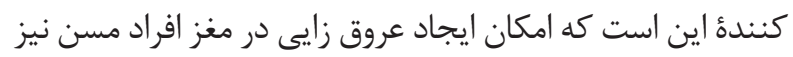

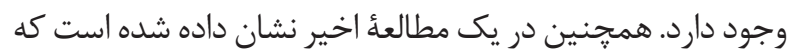

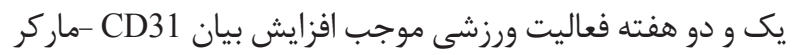

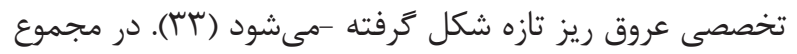

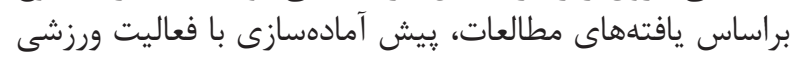

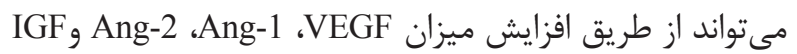

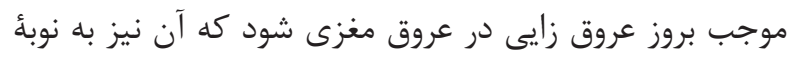

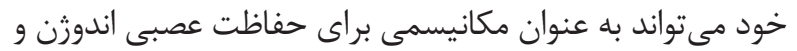
افزايش مقاومت ايسكميك در مغز عمل كند ماند

جزء مهم ديكر واحد عصبى -عروقى آستروسيتها هستند

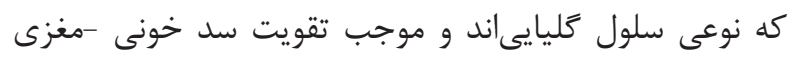

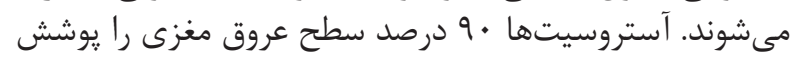

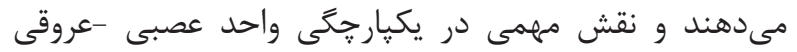

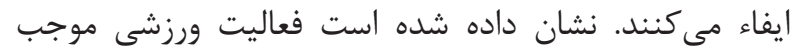

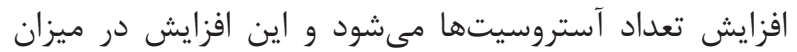

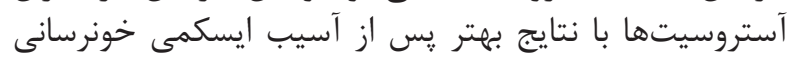

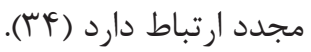

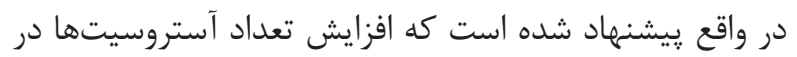

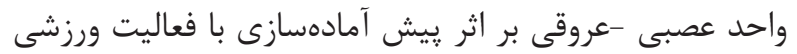

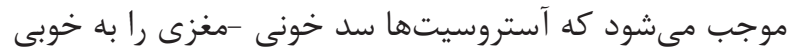

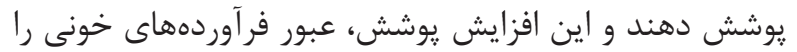

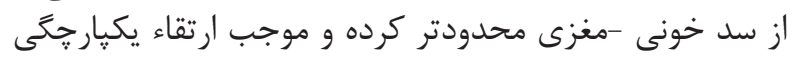

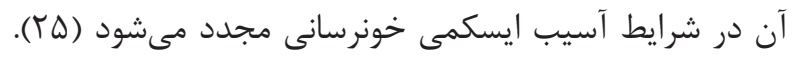

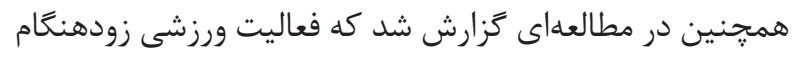

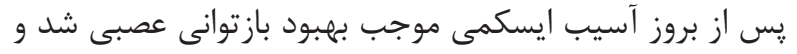

آستروسيتها نقش مهمى در اين فرايند داشتند (هـ").

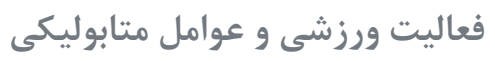

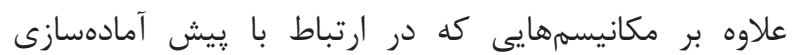

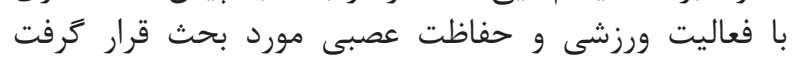

${ }^{18}$ Extracellular regulated kinase 1/2 (ERK 1/2)

${ }^{19}$ Tumor necrosis factor alpha (TNF- $\alpha$ )

${ }^{20}$ Aquaporin-4

${ }^{21}$ Heat shock proteins-70

${ }^{22}$ Magnetic resonance imaging (MRI)

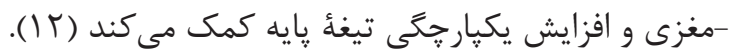

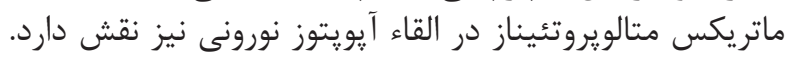

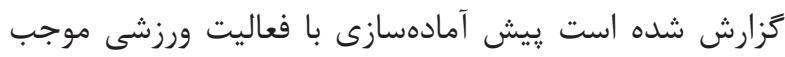

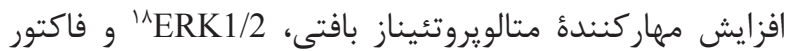
نكروز تومور -آلفا (TNF-

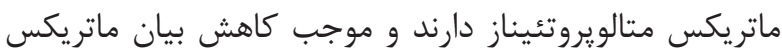

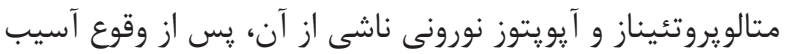

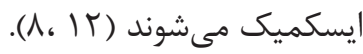

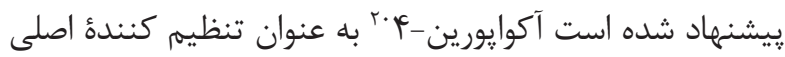

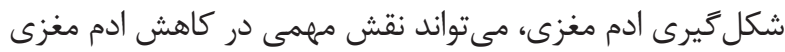

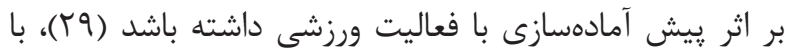

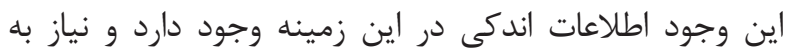

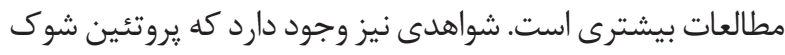

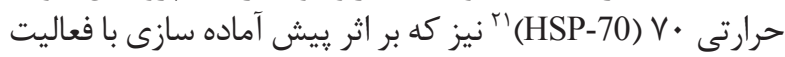

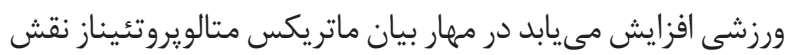

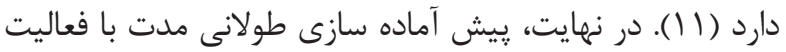

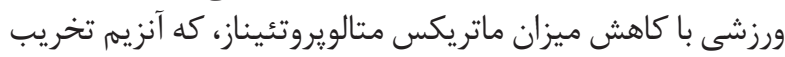

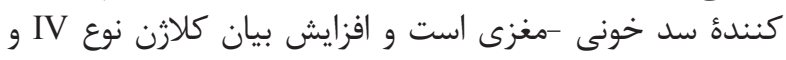

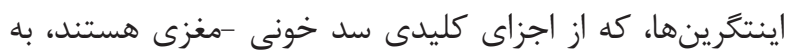

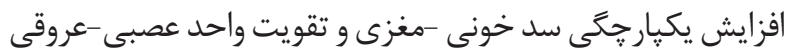
و در نتيجه ايجاد حفاظت عصبى منجر مئى

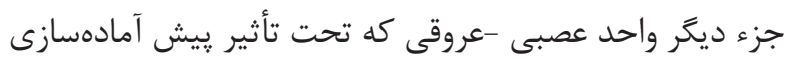

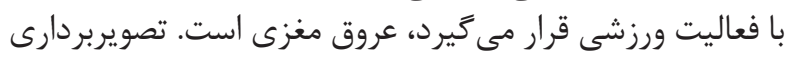

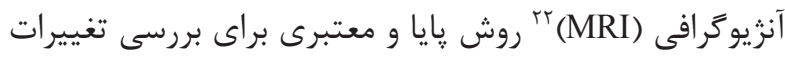

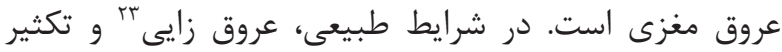

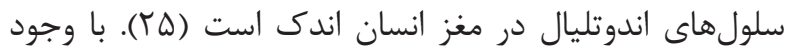

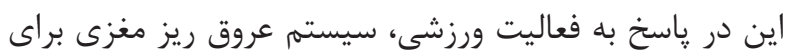

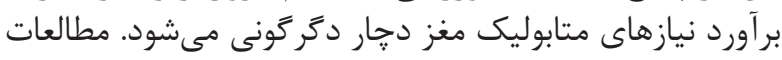

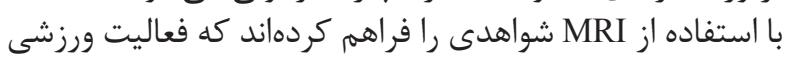

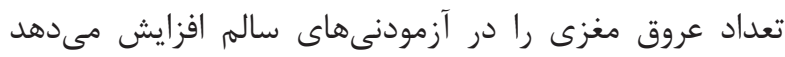

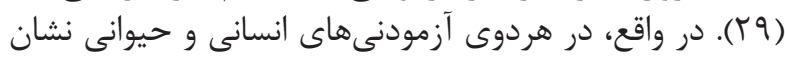

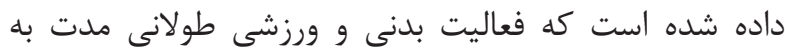

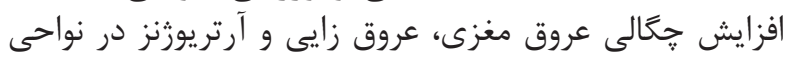

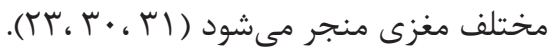

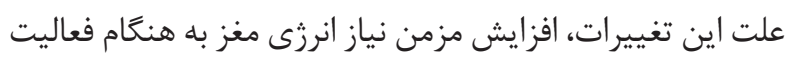

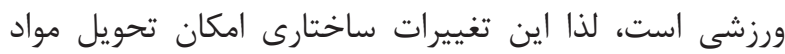

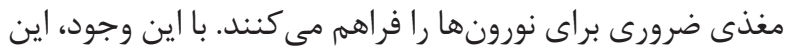

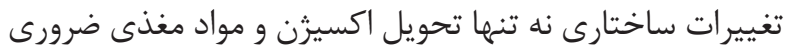

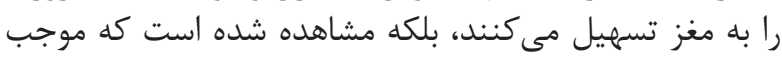

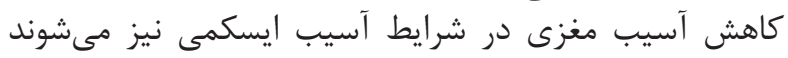

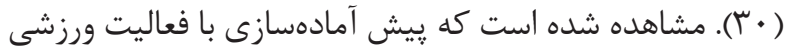

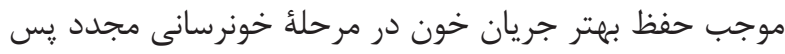

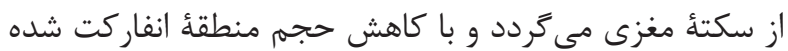

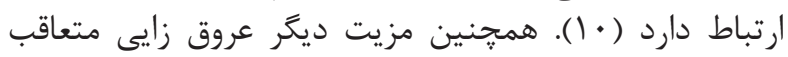

\footnotetext{
${ }^{23}$ Angiogenesis

${ }^{24}$ Collateral circulation

${ }^{25}$ Vascular endothelial growth factor

${ }^{26}$ Angiopoietin 1/2

${ }^{27}$ Insulin-like growth factor-1
} 


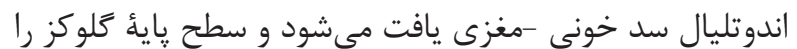
براى سلول ها فراهم مى كند؛

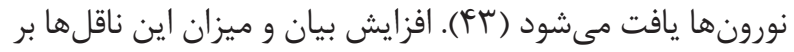

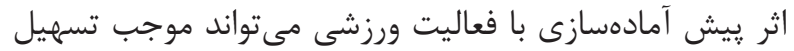

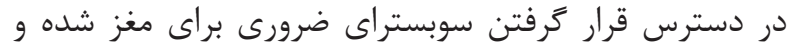

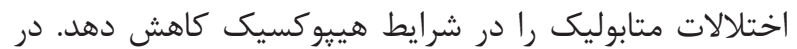

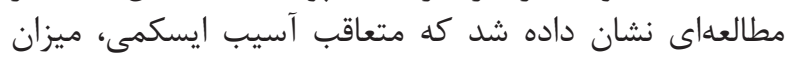

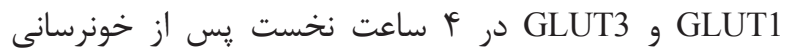

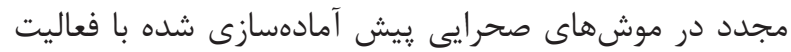

$$
\text { ورزشى افزايش يافت (FT) (F). }
$$

با توجه به نقش GLUT ها در تأمين سوبستراى انرزى مورد نياز

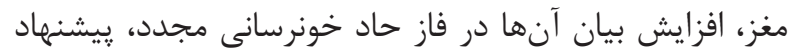

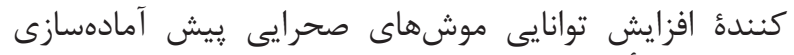

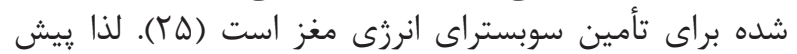

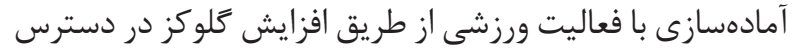

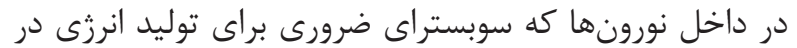

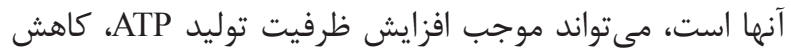

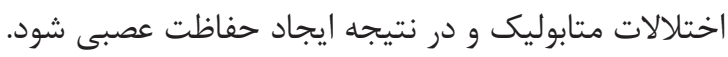

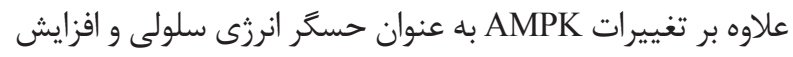

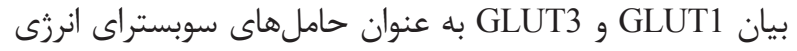

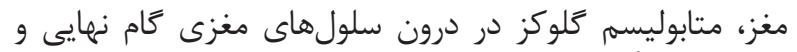

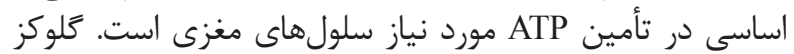

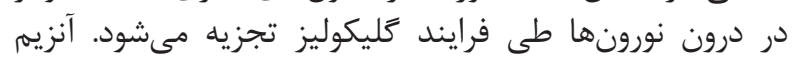

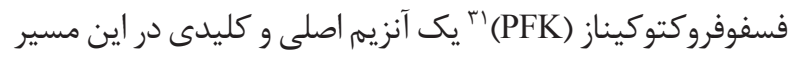

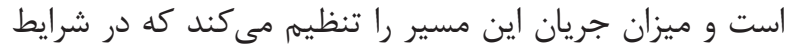
هييوكلايسميك داراى اثرات حفاظت عصبى است (9 (1).

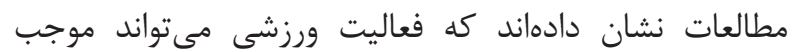

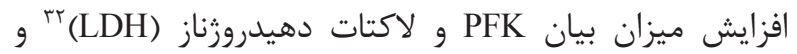

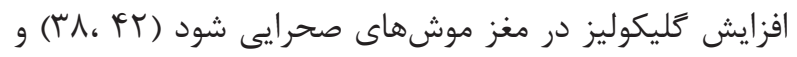

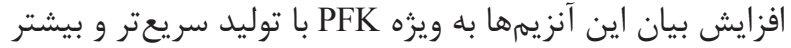

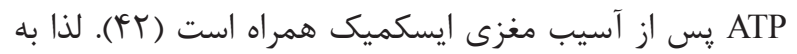

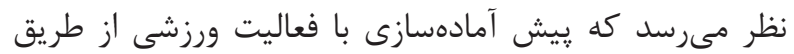

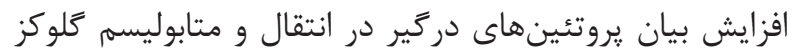

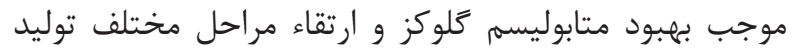

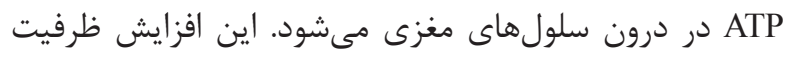

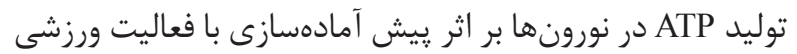

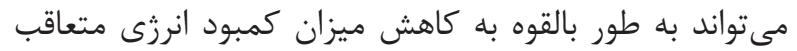

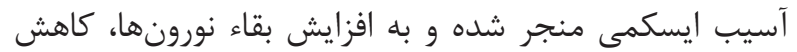

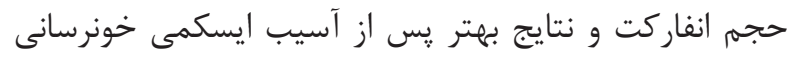
مجدد منجر شود.

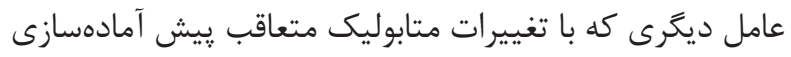

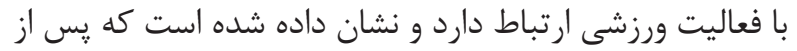

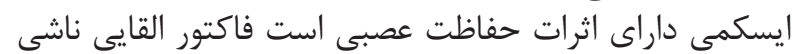

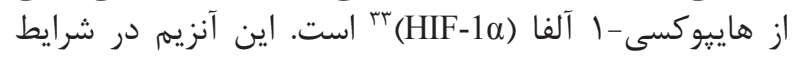
طبيعى توسط هيدروكسيلازهاى وابسته به اكسيزن آنه مهار

${ }^{28}$ Adenosine triphosphate (ATP)

${ }^{29}$ Adenosine monophosphate activated protein kinase

${ }^{30}$ Glucose transporter
مشخص شده است كه تمرين ورزشى طولانى مدت متابوليسم

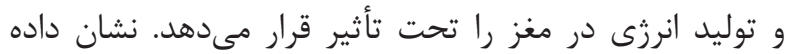

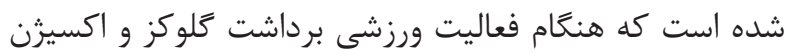

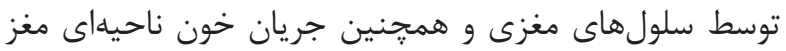

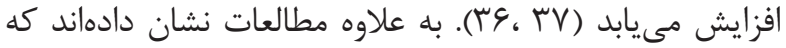

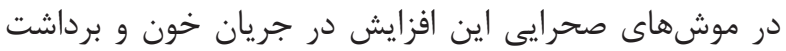

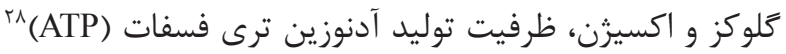

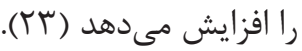

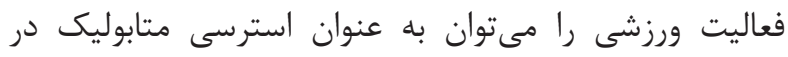

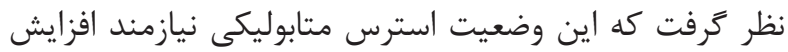

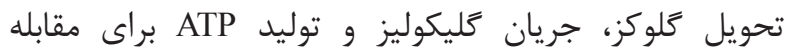

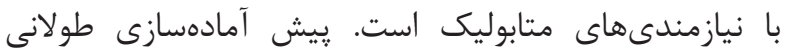

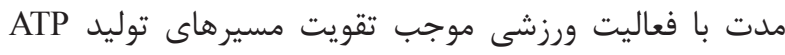

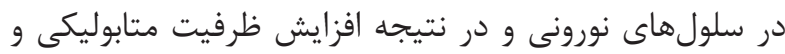

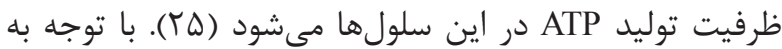

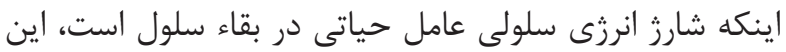

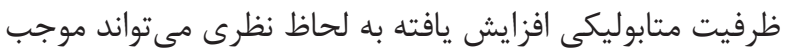

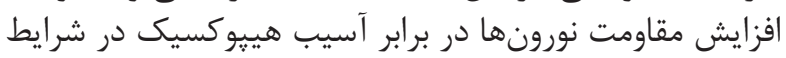
آسيب ايسكمى خونرسانى مجدد شود درد

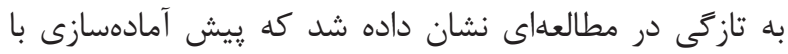

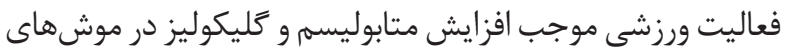

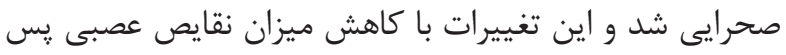

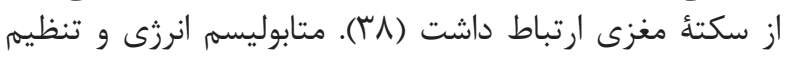

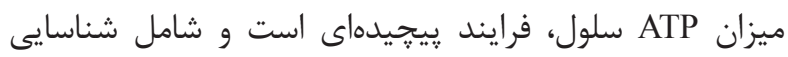

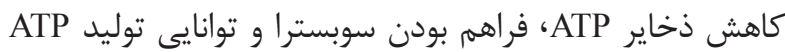

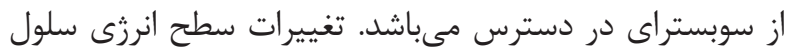
توسط يروتئين كيناز فعال شده توسط

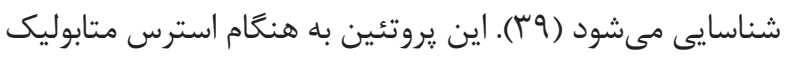

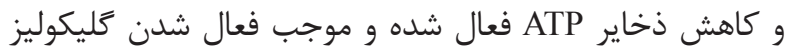

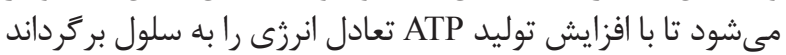

. (r山, r. )

مشخص شده است كه بيش آمادهسازى با فعاليت ورزشى

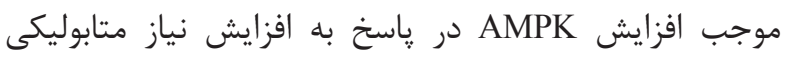

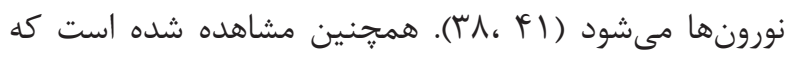

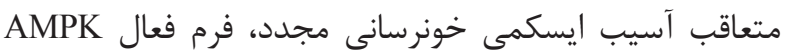

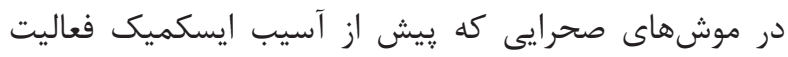

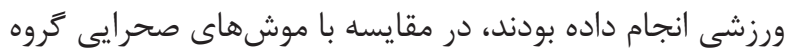

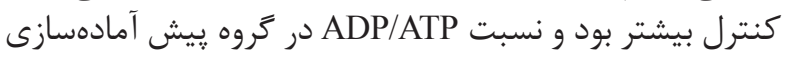

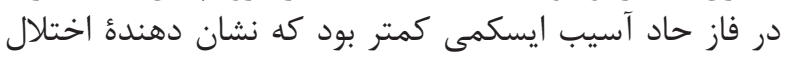

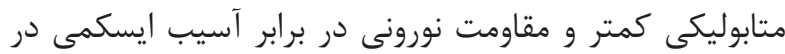

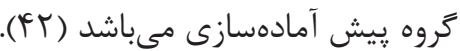

به علاوه گزارش شده است كه بيش آمادهسازى با فعاليت

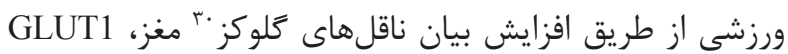

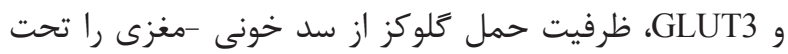

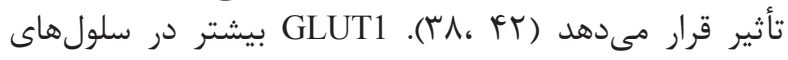

\footnotetext{
${ }^{31}$ Phosphofructokinase

${ }^{32}$ Lactate dehydrogenase

${ }^{33}$ Hypoxia inducible factor- $1 \alpha$
} 
برخى مطالعات نشان دادهاند كه در موشهاى صحرايى انجام

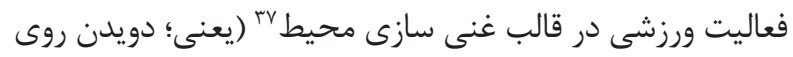

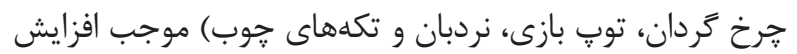

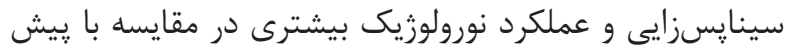

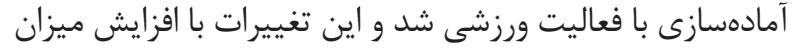

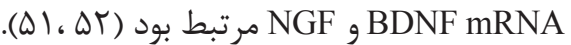

به نظر مىرسد كه اين تنظيم افزايشى ميزان نوروتروفينها

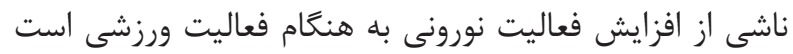

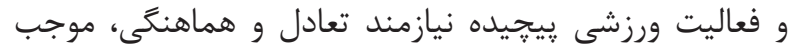

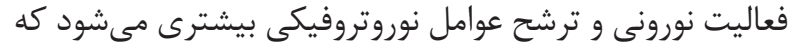

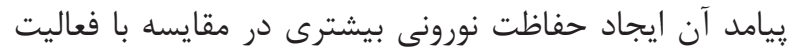

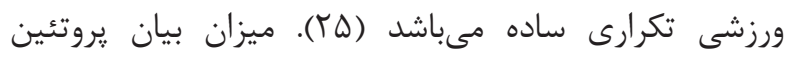

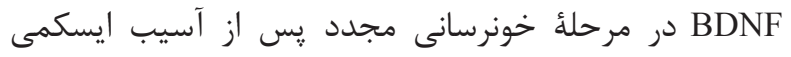

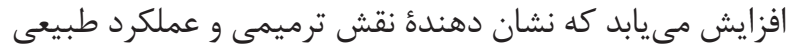

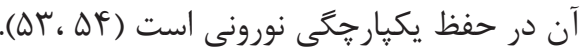

مطالعات نشان دادهاند در موشهاى صحرايى كه در آنها برايش

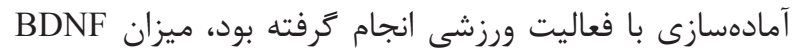

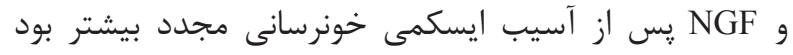

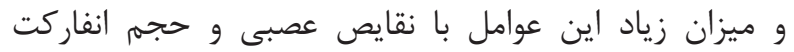

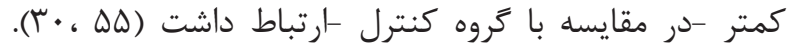

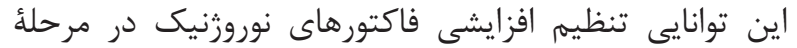

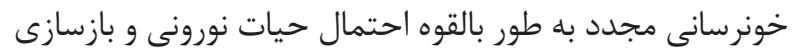

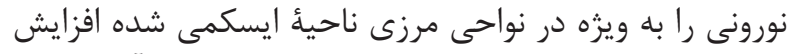

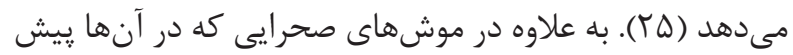

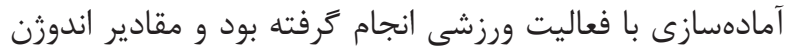

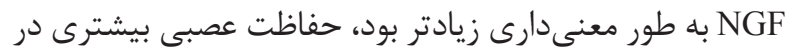

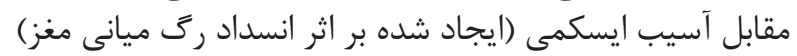

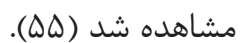

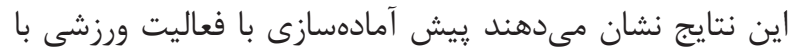

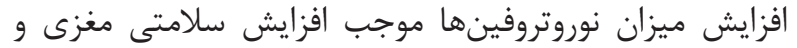

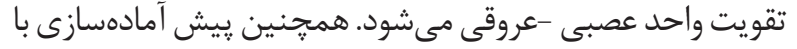

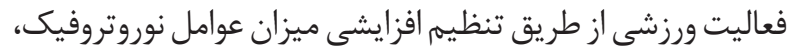

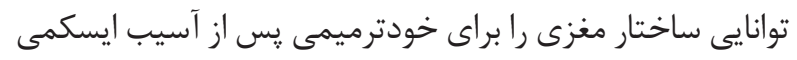

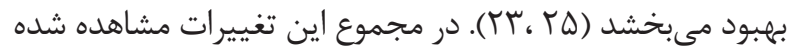

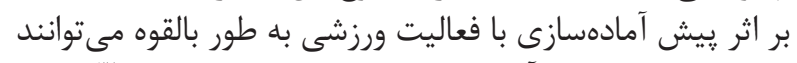

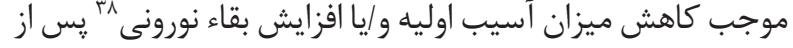

آسيب ايسكمى خونرسانى مجدد شوند.

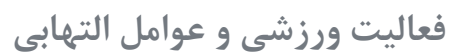

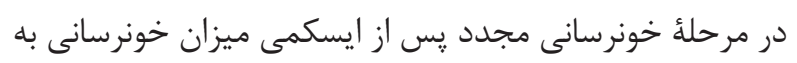

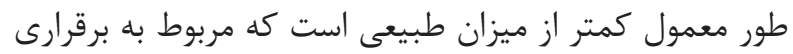

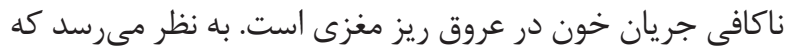

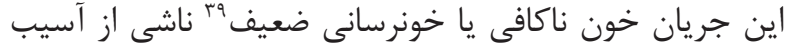

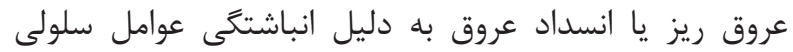

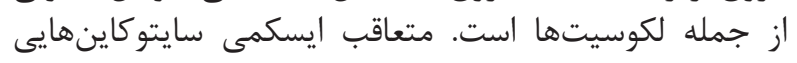

${ }^{34}$ Brain derived neurotrophic factor (BDNF)

${ }^{35}$ Nerve growth factor (NGF)

${ }^{36}$ Neurotrophin-3

${ }^{37}$ Environmental facilitation
مىشود. هاييوكسى و AMPK موجب تحريك نسخه بردارى

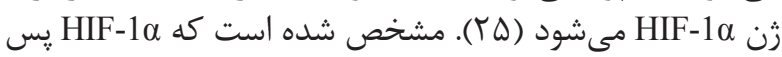

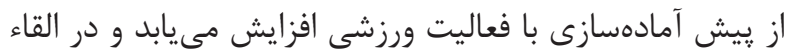

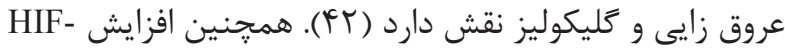

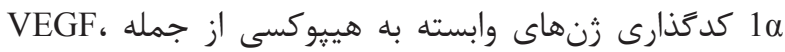

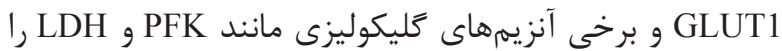

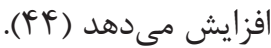

لذا به نظر مىرسد كه فعاليت ورزشى به واسطئ افزايش مصرف

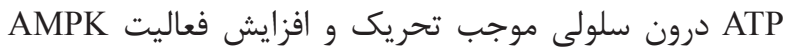

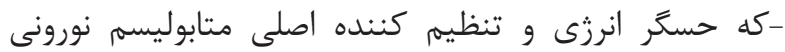

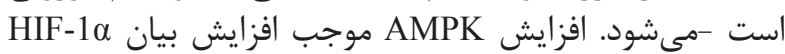

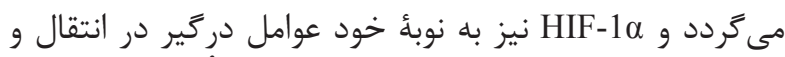

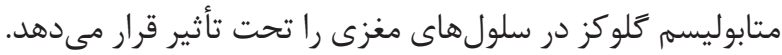

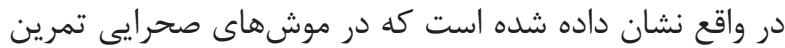
كرده، سطوح افزايش يافته

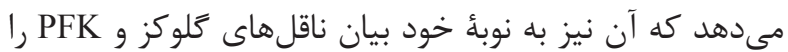

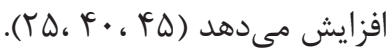

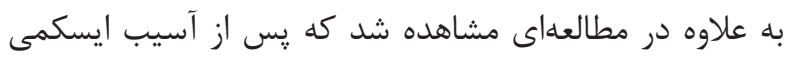

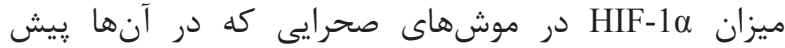

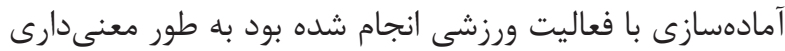

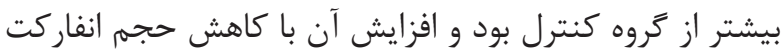

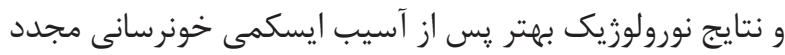

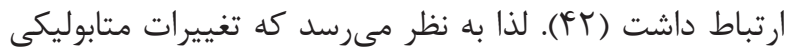

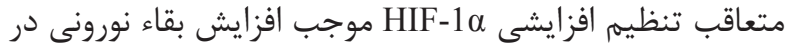

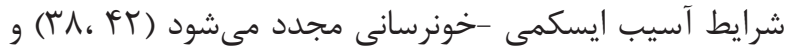

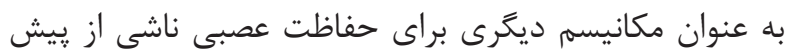
آمادهسازى با فعاليت ورزشى عمل ميكى مكند.

\section{فعاليت ورزشى و عوامل نوروتروفيك باليك}

عوامل نوروتروفيك يا نوروتروفينها مولكولهايى يروتئينىاند

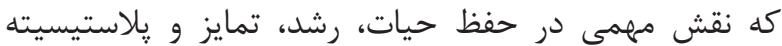

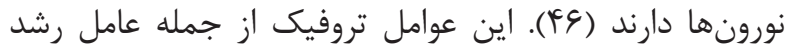

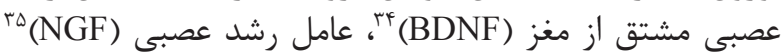

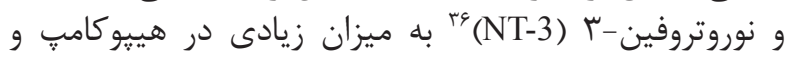

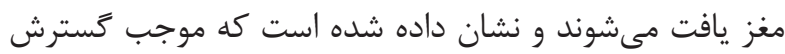

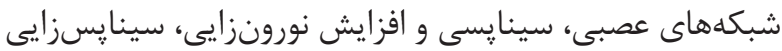

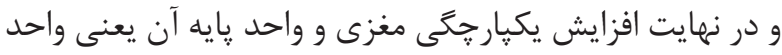

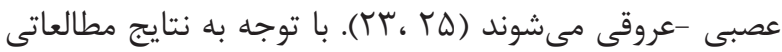

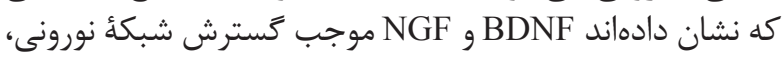

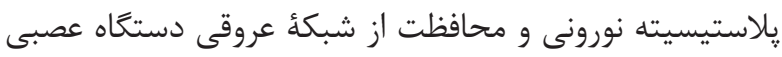

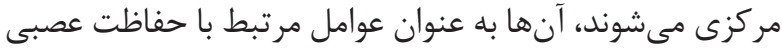

معرفى شدهاند (T)، FV)

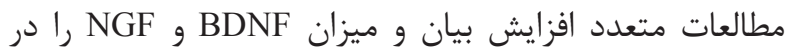

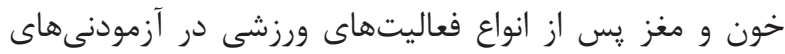

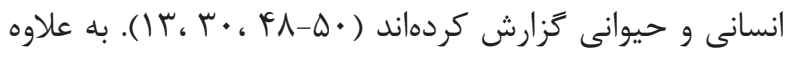

\footnotetext{
${ }^{38}$ Neuronal survival

${ }^{39}$ Hypoperfusion

${ }^{40}$ Interleukin-1
} 
يك عامل مضر شناخته شده است، اما مشخص شده است كه

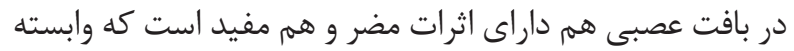

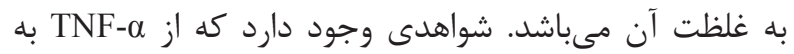

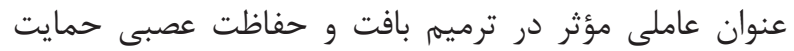

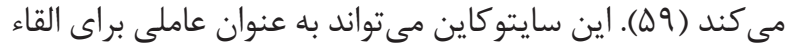

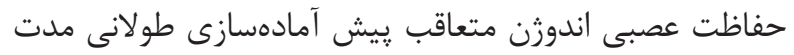

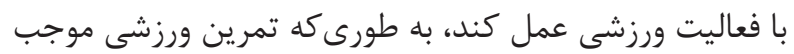

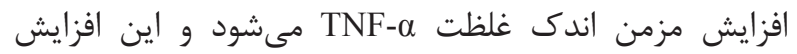

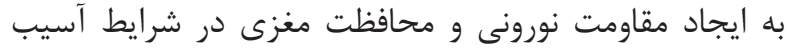

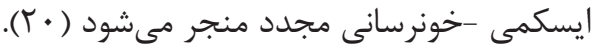

ضمن اينكه نشان داده شده است مهار بيان يا آزاد شدان TNF- $\alpha$

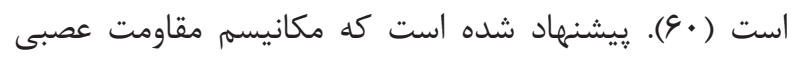

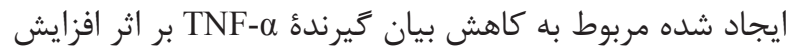

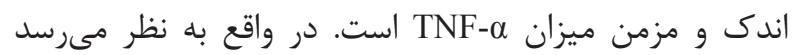

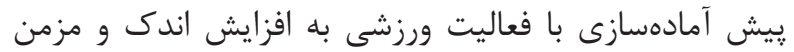

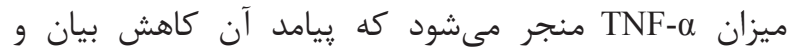

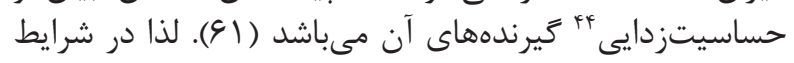

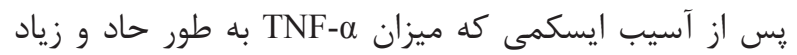

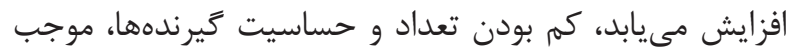
كاهش اثرات مضر TNF-

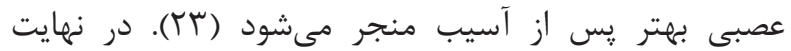

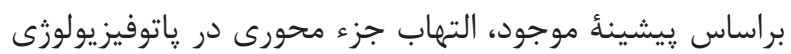

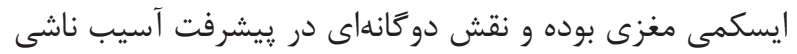

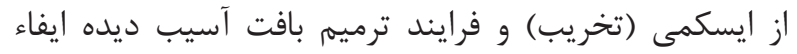

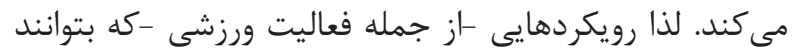

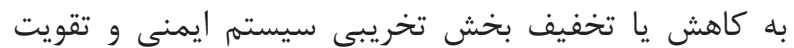

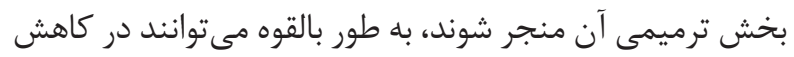

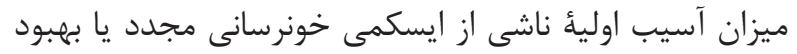
نتايج يس إز آن منجر شوند.

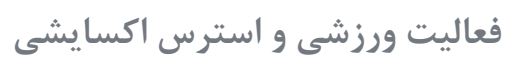

شواهد زيادى وجود دارد كه راديكال هاى آزاد در پاتوزنز آسيب

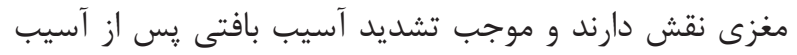

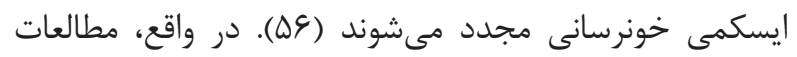

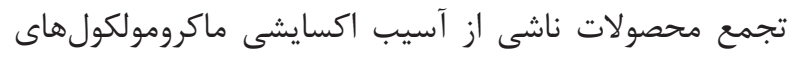

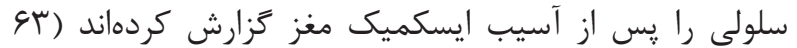

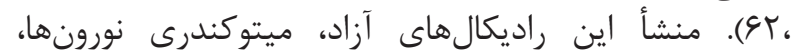

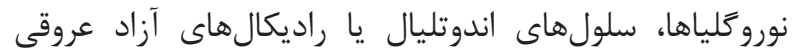

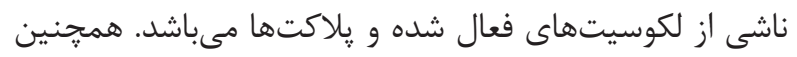

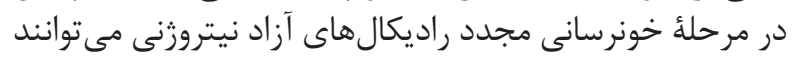

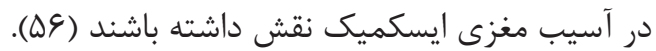

شواهد قوى وجود دارد كه راديكال آزاد سوير اكسيد توليد

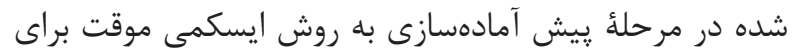

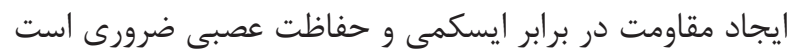

\footnotetext{
${ }^{41}$ Intracellular adhesion molecule-1

${ }^{42} \mathrm{P}$-selectin
}

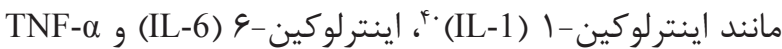

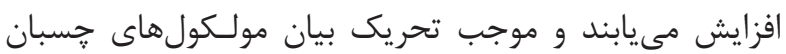

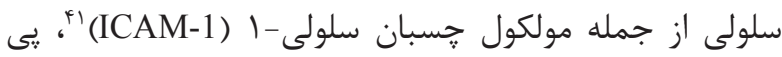

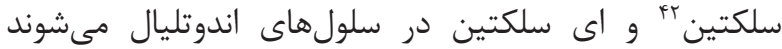

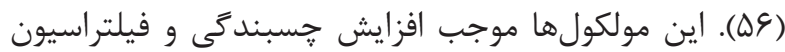

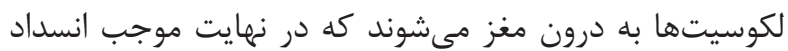

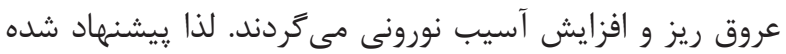

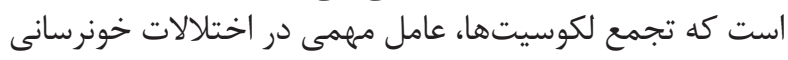

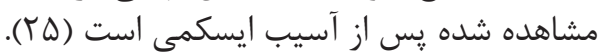

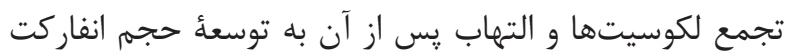

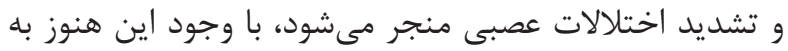

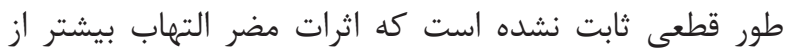

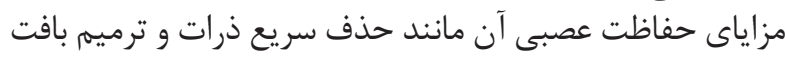

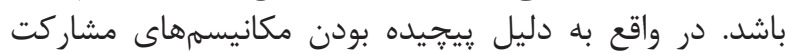

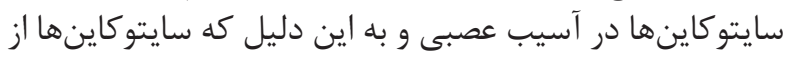

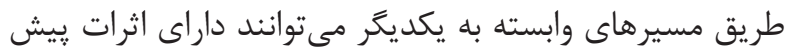

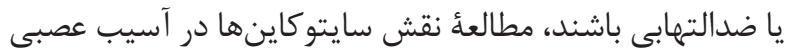

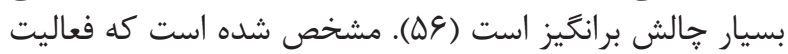

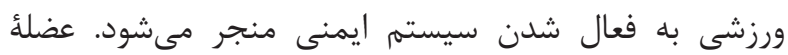

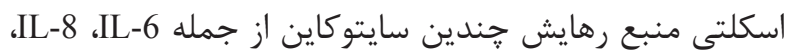

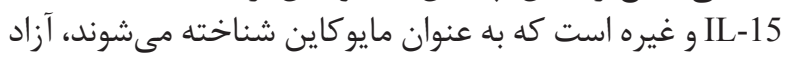

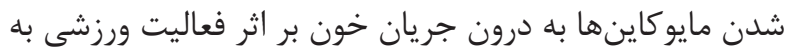

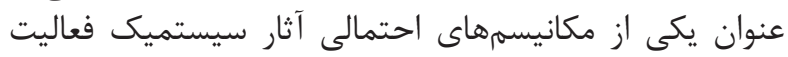

ورزشى از جمله حفاظت عصبى معرفى شده است (DV)

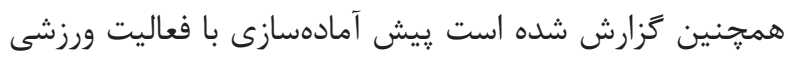

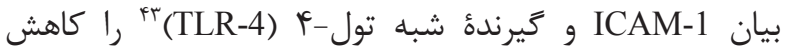

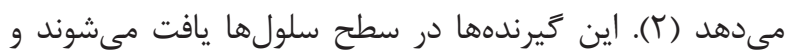

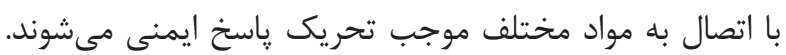

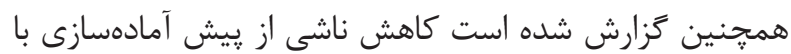
فعاليت ورزشى در بيان TLR-4 و

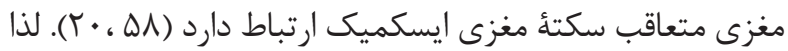

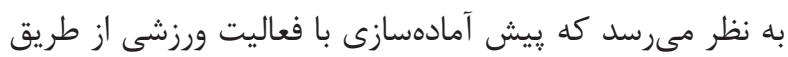

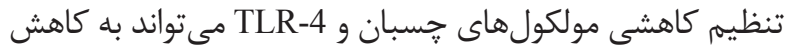

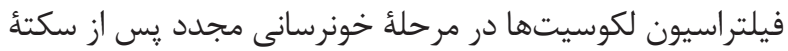

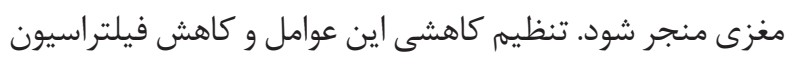

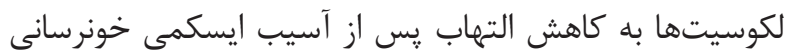

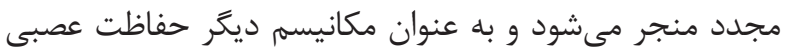
ناشى از ييش آمادهسازى با فعاليت ورزشى عمل مئى كند.

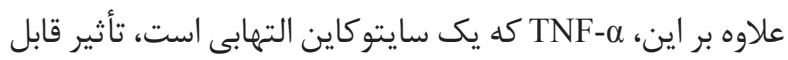

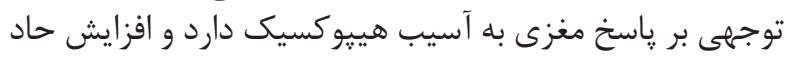

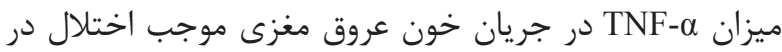

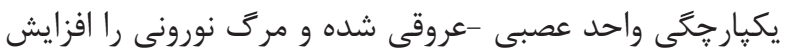

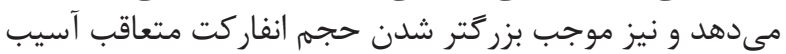

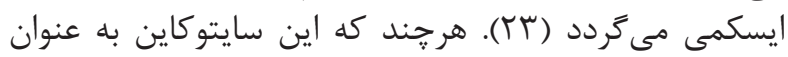

\footnotetext{
${ }^{43}$ Toll-like receptor

${ }^{44}$ Desensitization
} 
در واقع مرك يا بقاى نورونى متعاقب آسيب ايسكمى خونرسانى

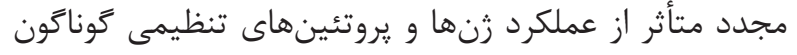

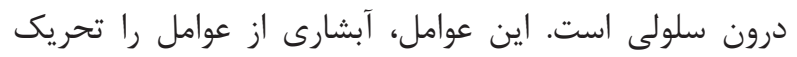

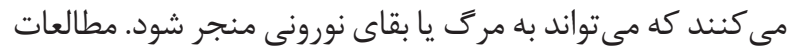

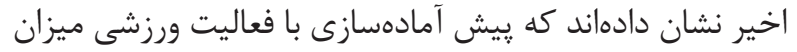

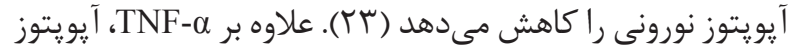

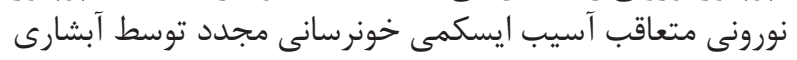

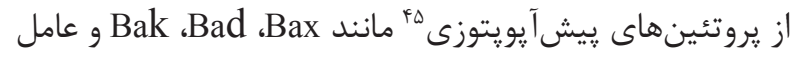

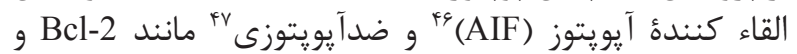
(9cl-xL

كزارش شده است كه بيش آمادهسازى با فعاليت ورزشى

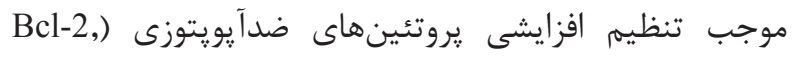
(Bcl-xL و افزايش نسبت يروتئينهاى (Bax, Bad, and Bak, AIF)

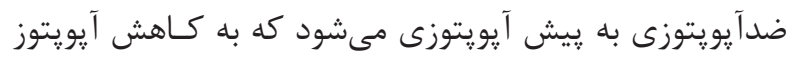

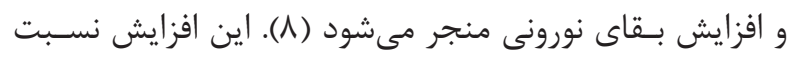

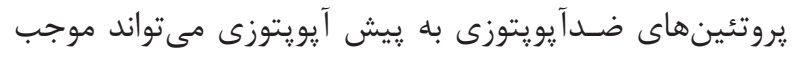

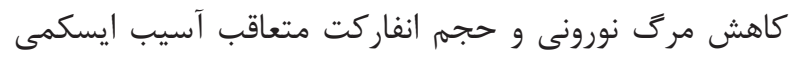
خونرسانى مجدد شود.

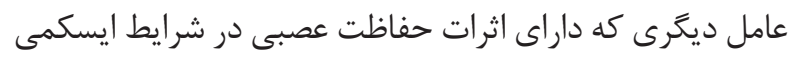

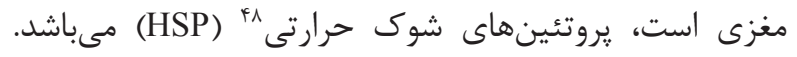

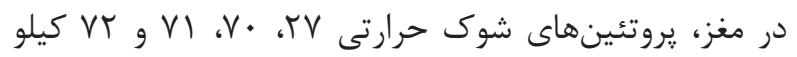

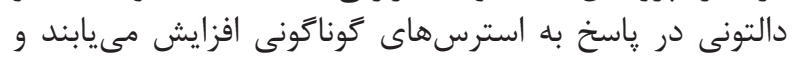

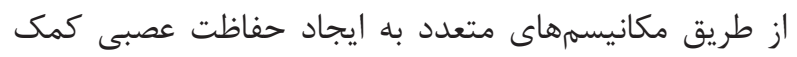

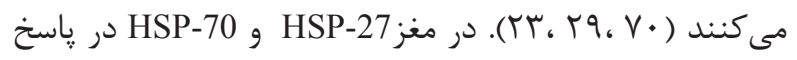

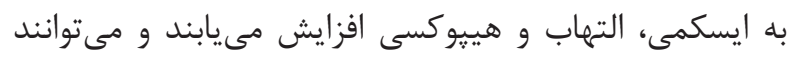

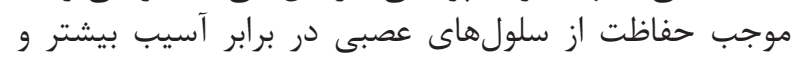

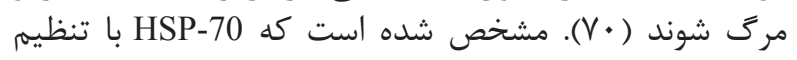

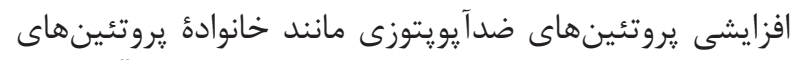

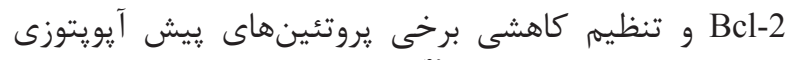

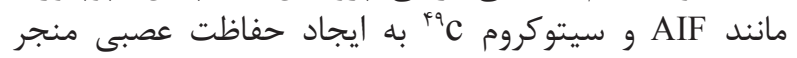

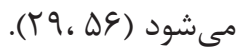

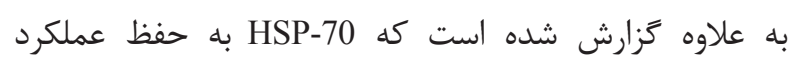

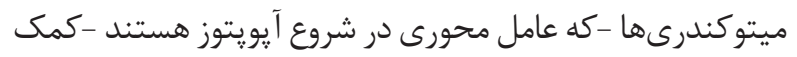

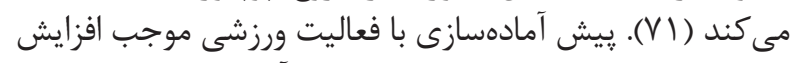

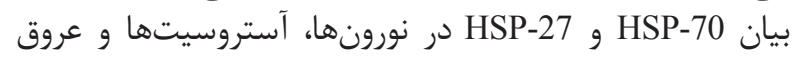

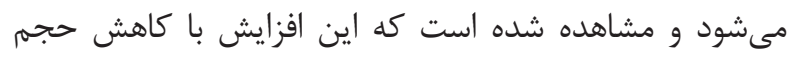

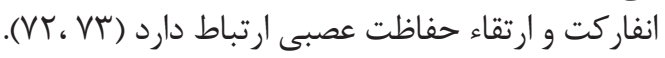

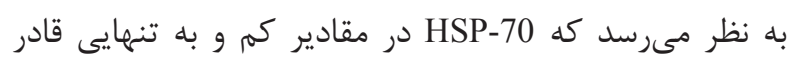
به ايجاد اثر حفاظت عصبى نيست نيست و عملكرد

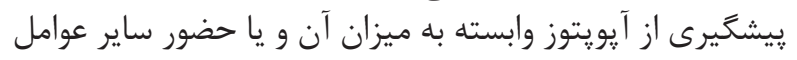

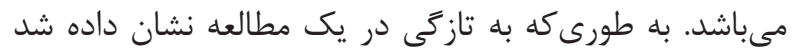

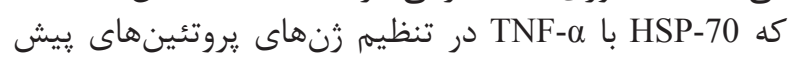

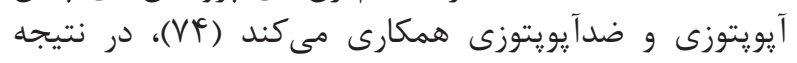

${ }^{45}$ Preapoptotic

${ }^{46}$ Apoptosis inducing factor

${ }^{47}$ Antiapoptotic
(GF)

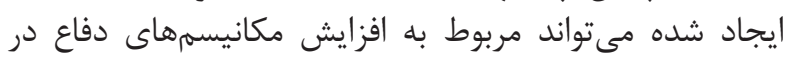

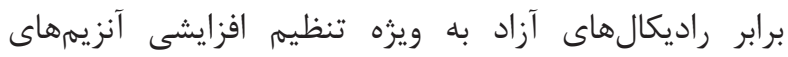

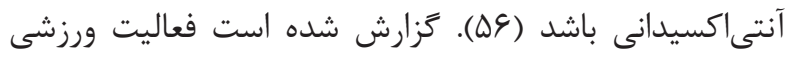

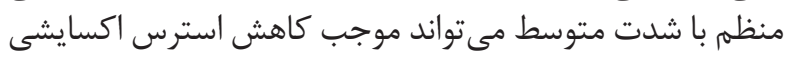

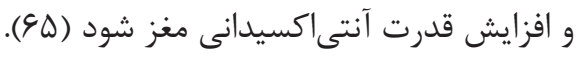

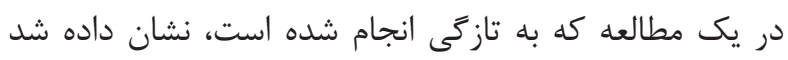

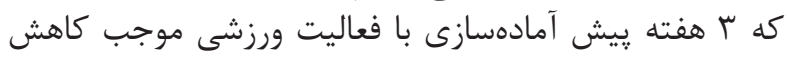

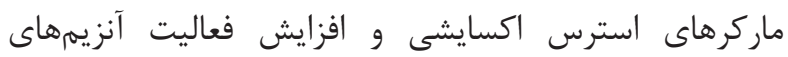

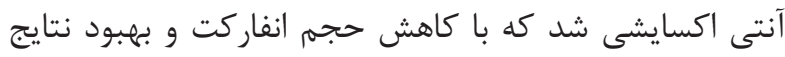

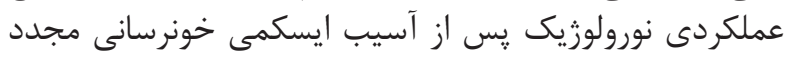

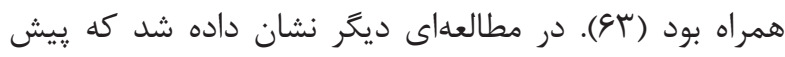

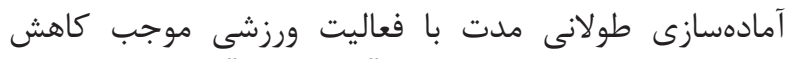

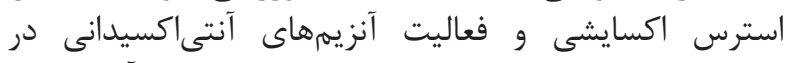

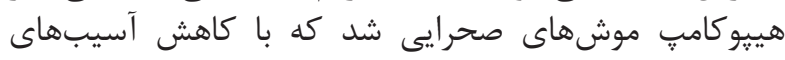

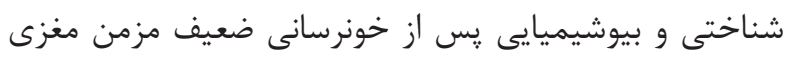

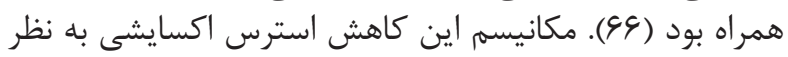

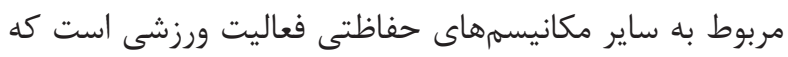

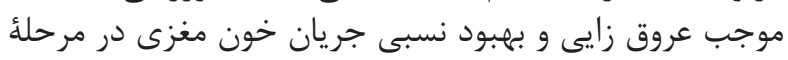
ايسكمى مىشوند (ساع).

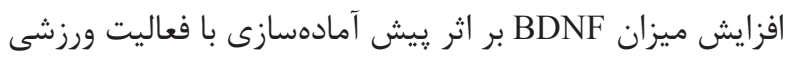

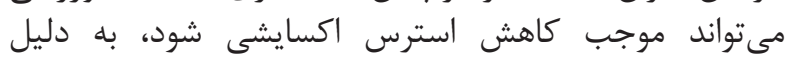

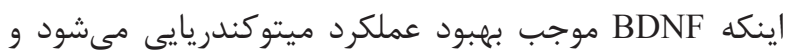

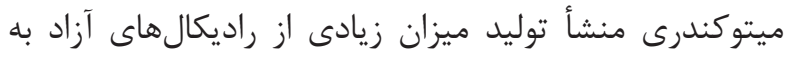

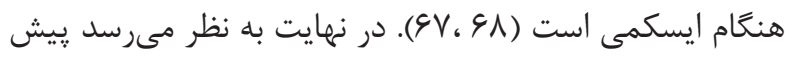

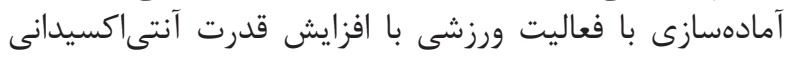

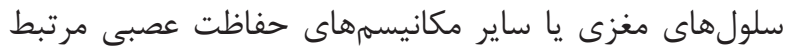

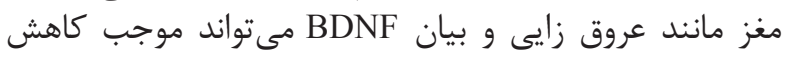

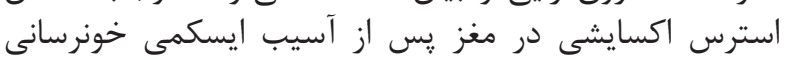

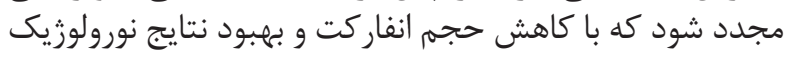
يس از آسيب ايسكميك ارتباط دارد.

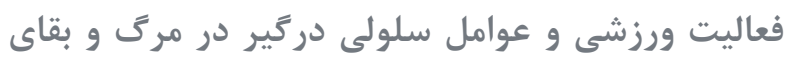

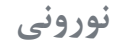

نكروز نوع اصلى مركى سلولى در مركز ناحيةٔ ايسكمى به شمار

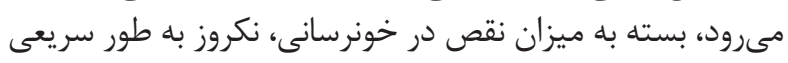

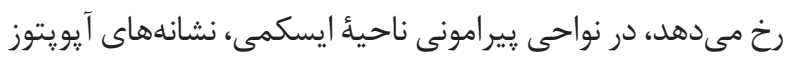

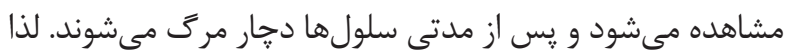

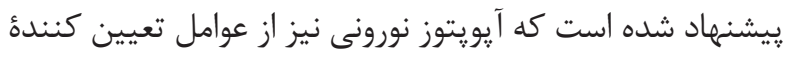

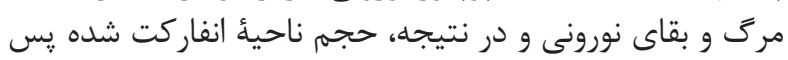

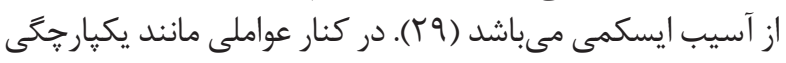

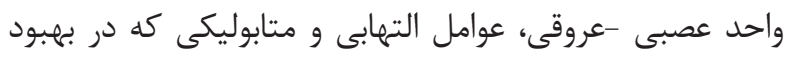

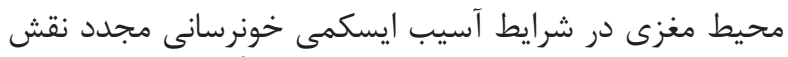

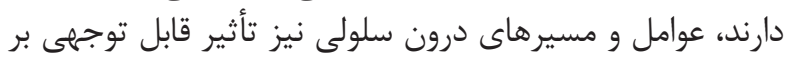

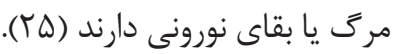

\footnotetext{
${ }^{48}$ Heat shock proteins

${ }^{49}$ Cytochrome c
} 
و تحريك زياد كيرندههاى آن از جمله كَيرندة متابوتروفيك

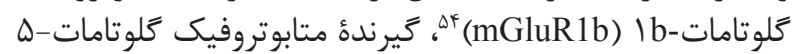
و و كيرندة ان متيل دى آسيارتات (mGluR5)

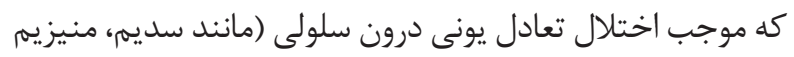

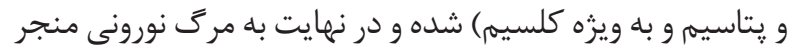

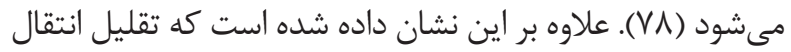

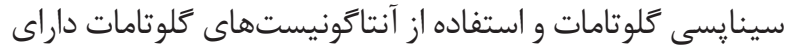

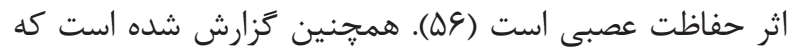

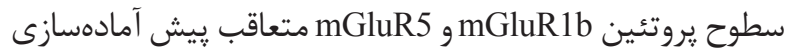

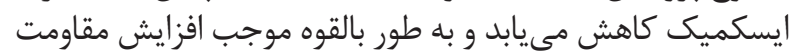

در برابر ايسكمى مىشود (1).

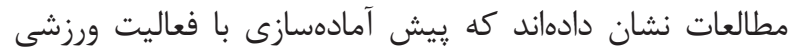

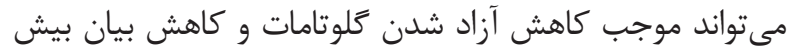

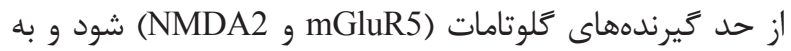

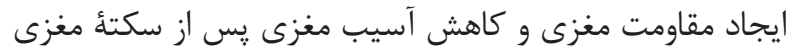

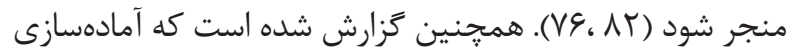

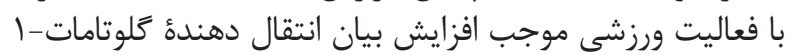

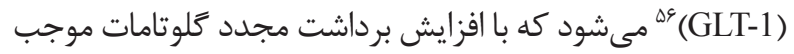

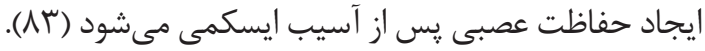

ميتوكندرى عامل ديخرى است كه نقش بسيار مهمى در مرك مرك

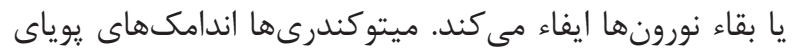

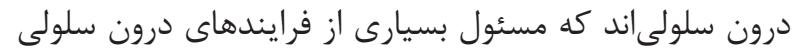

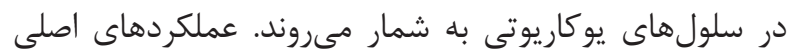

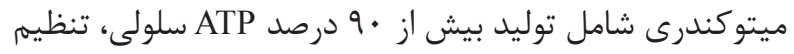

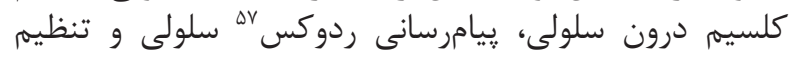

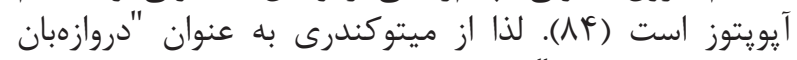

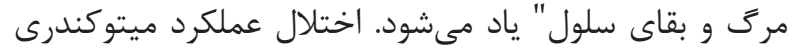

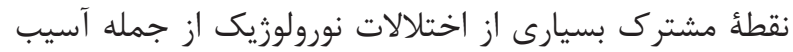

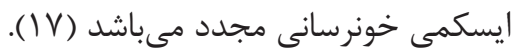

با توجه به نقش محورى ميتوكندرى در تأمين ATP سلولى و

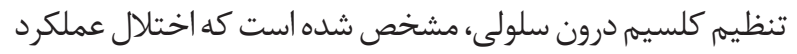

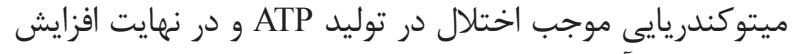

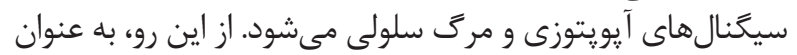

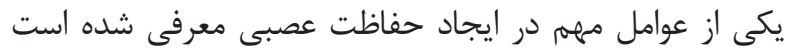

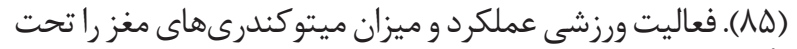

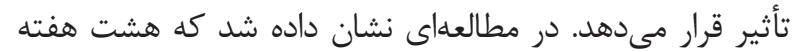

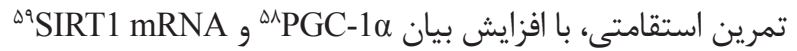

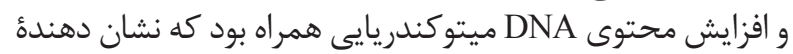

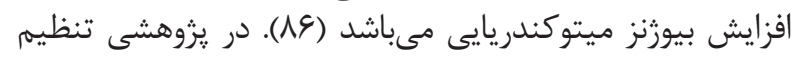

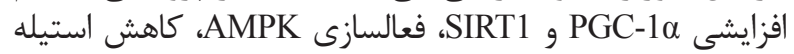

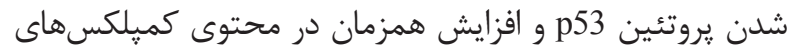

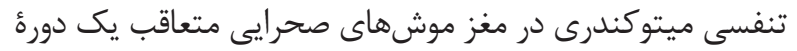
تمرين استقامتى كزارش شد دم موشن (AV).

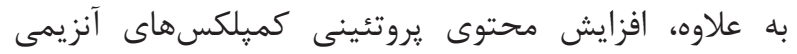
زنجيرء انتقال الكترون، افزايش نسبت ADP به به اكسيزن و

\footnotetext{
${ }^{50}$ Autophagy

${ }^{51}$ Neurotransmitter

${ }^{52}$ Neurotoxin

${ }^{53}$ Excitotoxicity

${ }^{54}$ Metabotropic glutamate receptor

${ }^{55} \mathrm{~N}$-methyl-D-Aspartate
}

ييشنهاد شده است كه احتمالاً ييش آمادهسازى با فعاليت

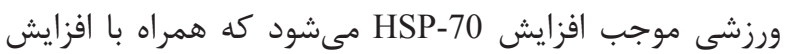

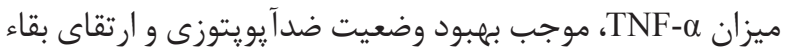

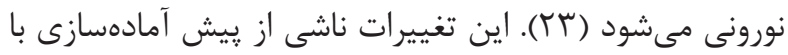

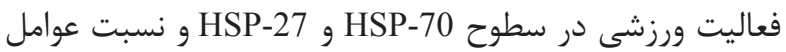

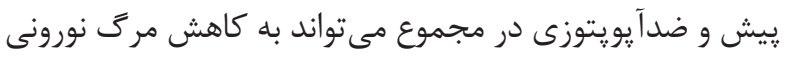

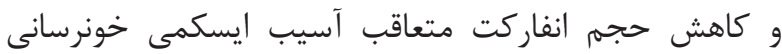

مجدد منجر شود.

همجنين نتايج برخى مطالعات نشان ميدهند إند مسير وابسته

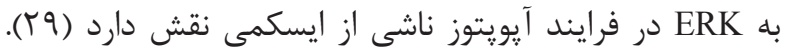

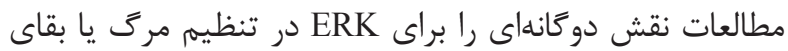

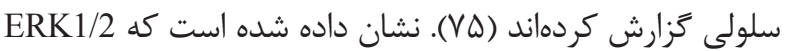

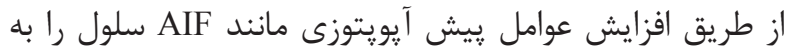

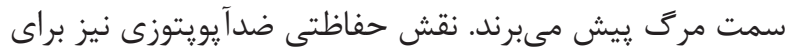

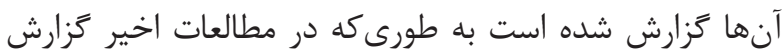

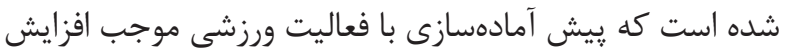

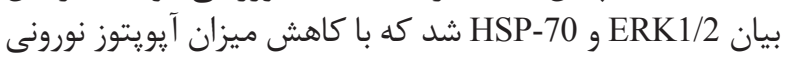

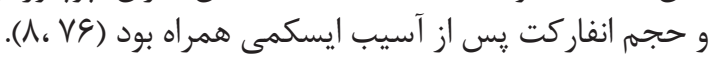

به نظر مىرسد نقش دو حانئ

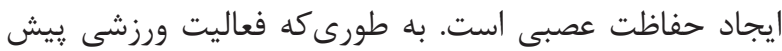

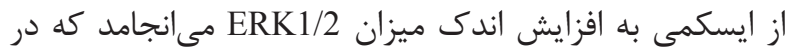

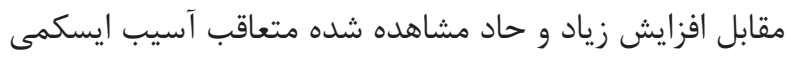

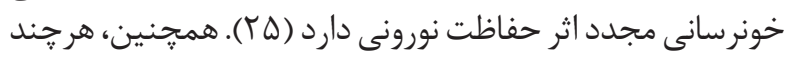

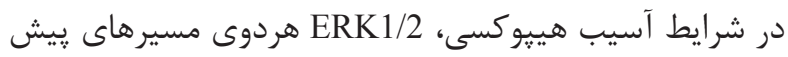

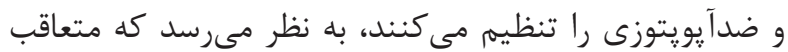

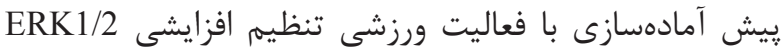

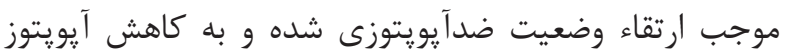

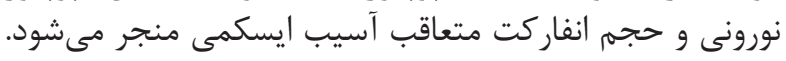

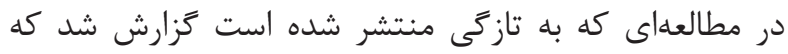

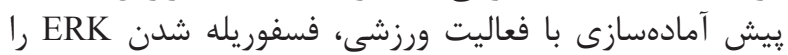

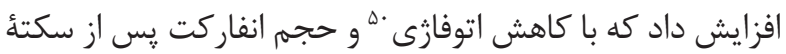
مغزى ايسكميك همراه بود (VV)

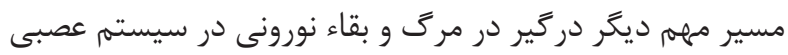

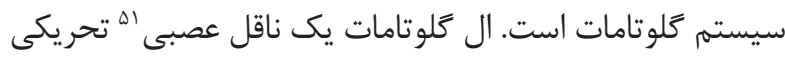

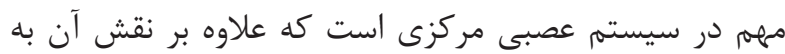

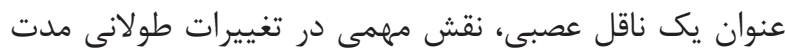

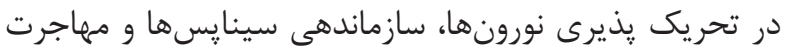

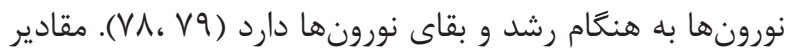

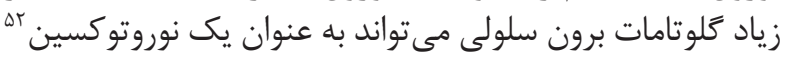

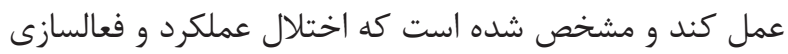

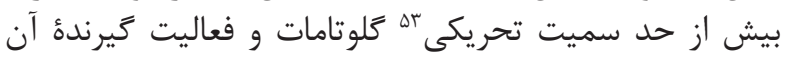

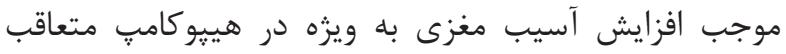

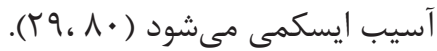

اثر سميت تحريكى كلوتامات ناشى از آزاد شدن بيش از حد حد

${ }^{56}$ Glutamate transporter-1

57 "Redox" means reduction/oxidation reactions, and signaling

${ }^{58}$ Peroxisome proliferator-activated receptor gamma coactivator 1-alpha (PGC-1 $\alpha$ )

${ }^{59}$ Silent information regulator T1 (SIRT1) 


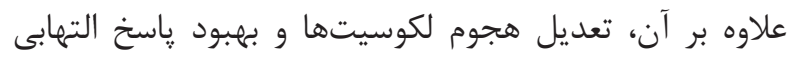

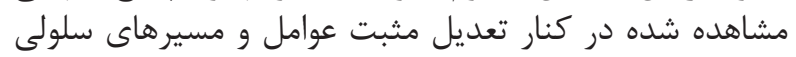

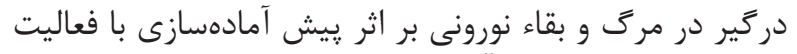

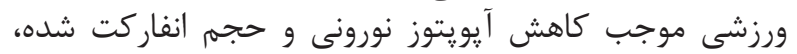

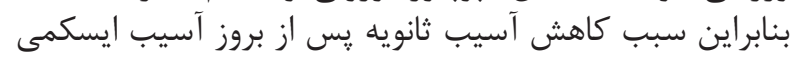

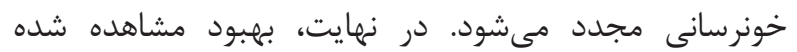

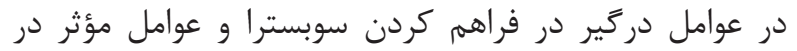

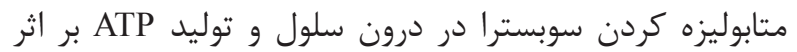

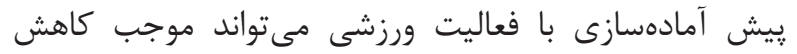

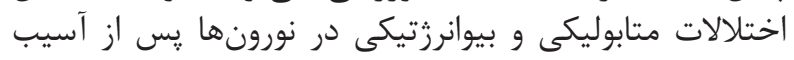

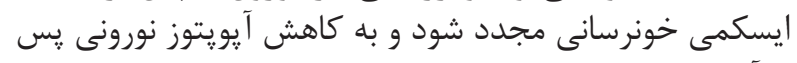

$$
\text { از آسيب ايسكمى منجر شود (نمودار (1). }
$$

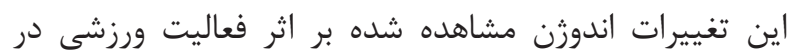

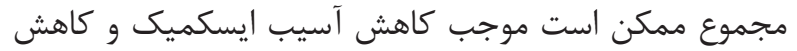

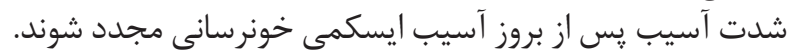

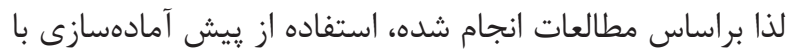

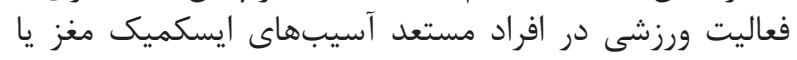

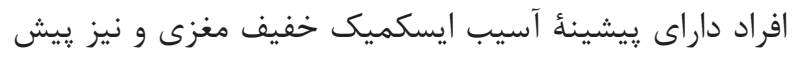

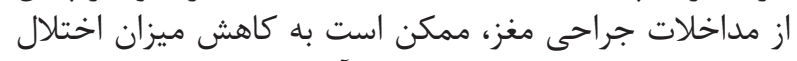

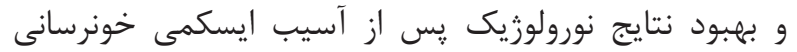

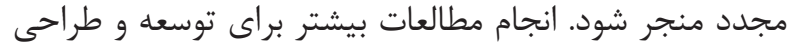

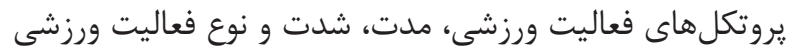
مناسب براى ايجاد حفاظت عصبى بهينه مورد نئ ونياز است.

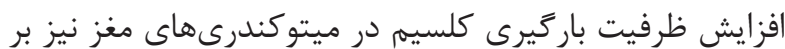

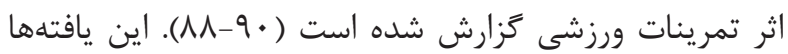

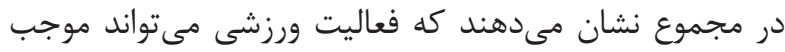

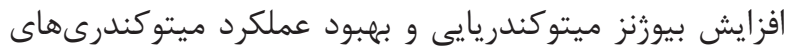

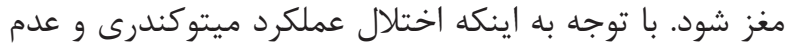

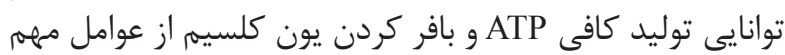

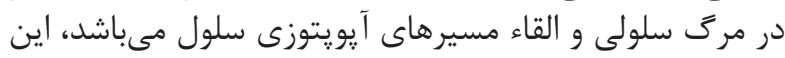

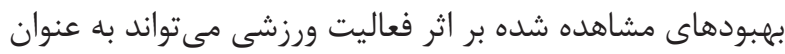

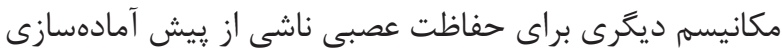
با فعاليت ورزشى عمل كند.

$$
\text { نتيجه كيرى }
$$

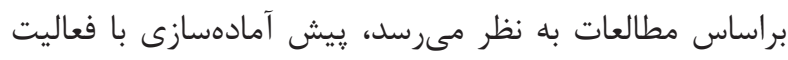

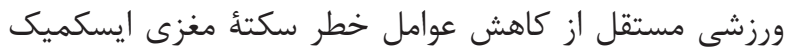

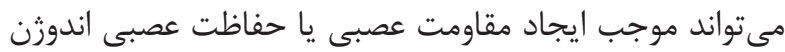

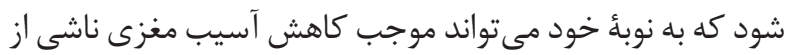

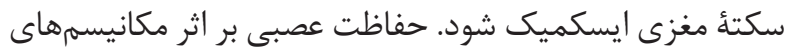

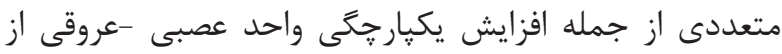

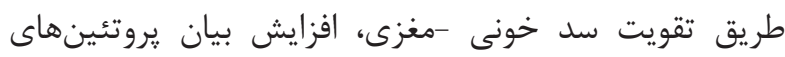

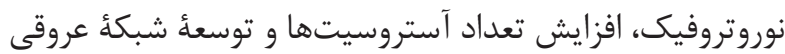

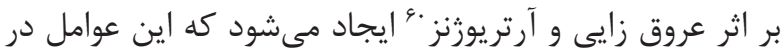

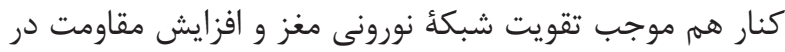
برابر آسيب ناشى از ايسكمى مى شوند.

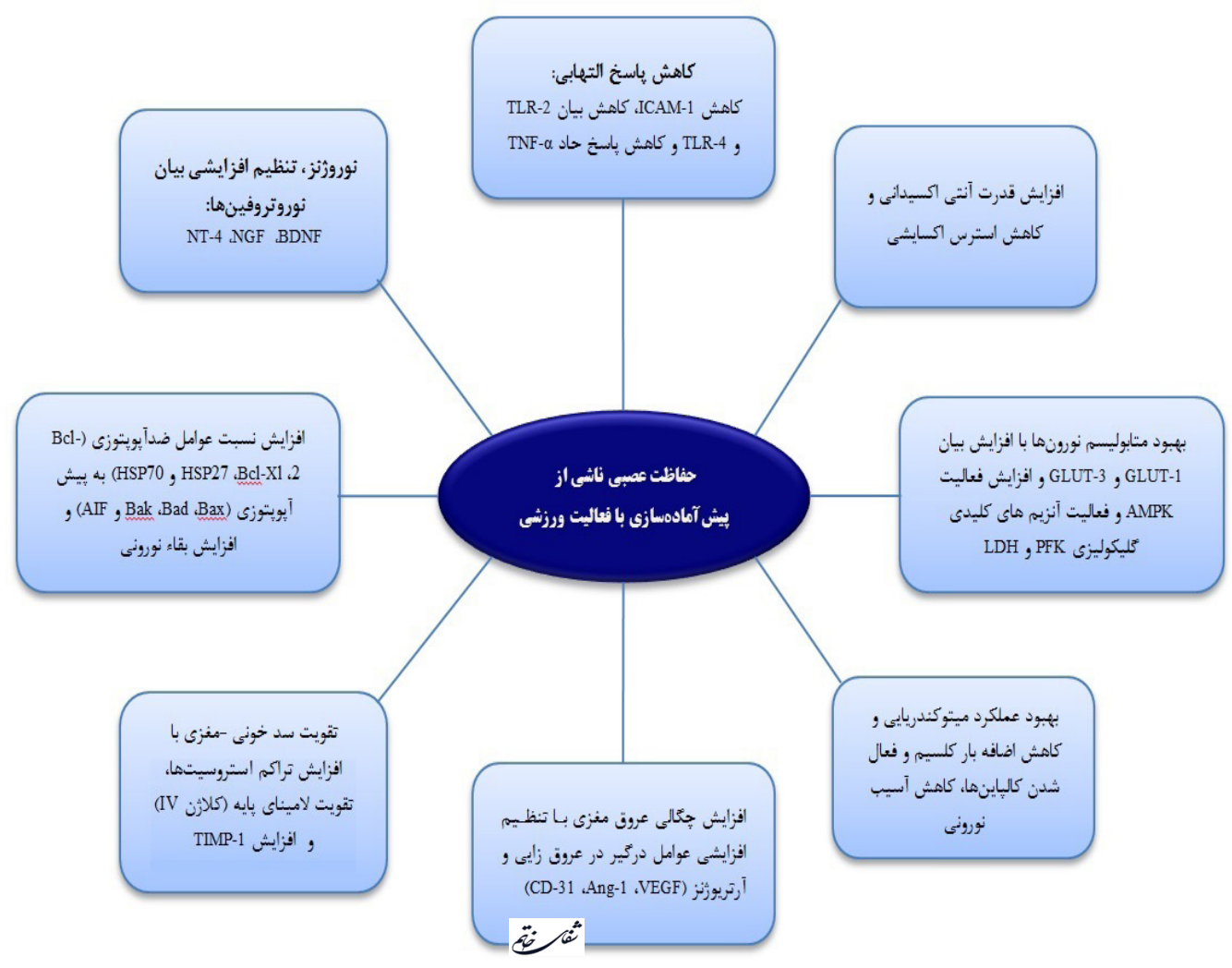

نمودار ا- خلاصهاى از مكانيسمهاى دركير در حفاظت عصبى ناشى از ييش آمادمسازى با فعاليت ورزشى.

${ }^{60}$ Arteriogenesis 
1. Flansbjer UB, Miller M, Downham D, Lexell J. Progressive resistance training after stroke: effects on muscle strength, muscle tone, gait performance and perceived participation. J Rehabil Med. 2008; 40(1): 42-8.

2. Khuram H. Effect of Aerobic Physical Training on Stroke Survivors. Umeå University. 2011.

3. Letombe A, Cornille C, Delahaye H, Khaled A, Morice O, Tomaszewski A, et al. Early post-stroke physical conditioning in hemiplegic patients: A preliminary study. Ann Phys Rehabil Med. 2010; 53(10): 632-42.

4. Yokobori S, Mazzeo AT, Hosein K, Gajavelli S, Dietrich WD, Bullock MR. Preconditioning for Traumatic Brain Injury. Transl Stroke Res. 2013; 4(1): 25-39.

5. Hu G, Barengo NC, Tuomilehto J, Lakka TA, Nissinen A, Jousilahti P. Relationship of physical activity and body mass index to the risk of hypertension: a prospective study in Finland. Hypertension. 2003; 43(1): 25-30.

6. Curry A, Guo M, Patel R, Liebelt B, Sprague S, Lai $Q$, et al. Exercise pre-conditioning reduces brain inflammation in stroke via tumor necrosis factor- $\alpha$, extracellular signal-regulated kinase $1 / 2$ and matrix metalloproteinase-9 activity. Neurol Res. 2010; 32(7): 756-62.

7. Davis W, Mahale S, Carranza A, Cox B, Hayes K, Jimenez D, et al. Exercise pre-conditioning ameliorates blood-brain barrier dysfunction in stroke by enhancing basal lamina. Neurol Res. 2007; 29(4): 382-7.

8. Chaudhry K, Rogers R, Guo M, Lai Q, Goel G, Liebelt B, et al. Matrix metalloproteinase-9 (MMP-9) expression and extracellular signal-regulated kinase 1 and 2 (ERK1/2) activation in exercise-reduced neuronal apoptosis after stroke. Neurosci Lett. 2010; 474(2): 109-14.

9. Cotman CW, Berchtold NC, Christie LA. Exercise builds brain health: key roles of growth factor cascades and inflammation. Trends Neurosci. 2007; 30(9): 464-72.

10. Zwagerman N, Sprague S, Davis MD, Daniels B, Goel G, Ding Y. Pre-ischemic exercise preserves cerebral blood flow during reperfusion in stroke. Neurol Res. 2010; 32(5): 523-9.
11. Liebelt B, Papapetrou P, Ali A, Guo M, Ji X, Peng C, et al. Exercise preconditioning reduces neuronal apoptosis in stroke by up-regulating heat shock protein-70 (heat shock protein-72) and extracellular-signal-regulatedkinase 1/2. Neuroscience. 2010; 166(4): 1091-100.

12. Guo M, Cox B, Mahale S, Davis W, Carranza A, Hayes K, et al. Pre-ischemic exercise reduces matrix metalloproteinase- 9 expression and ameliorates bloodbrain barrier dysfunction in stroke. Neuroscience. 2008; 151(2): 340-51.

13. Hillman $\mathrm{CH}$, Erickson $\mathrm{KI}$, Kramer AF. Be smart, exercise your heart: exercise effects on brain and cognition. Nat Rev Neurosci. 2008; 9(1): 58-65.

14. Murry CE, Jennings RB, Reimer KA. Preconditioning with ischemia: a delay of lethal cell injury in ischemic myocardium. Circulation. 1986; 74(5): 1124-36.

15. Fairbanks SL, Brambrink AM. Preconditioning and postconditioning for neuroprotection: the most recent evidence. Best Pract Res Clin Anaesthesiol. 2010; 24(4): 521-34.

16. Dirnagl U, Meisel A. Endogenous neuroprotection: mitochondria as gateways to cerebral preconditioning? Neuropharmacology. 2008; 55(3): 433-44.

17. Correia SC, Santos RX, Perry G, Zhu X, Moreira PI, Smith MA. Mitochondria: the missing link between preconditioning and neuroprotection. J Alzheimers Dis. 2010; 20: 475-85.

18. Cadet JL, Krasnova IN. Cellular and molecular neurobiology of brain preconditioning. Mol Neurobiol. 2009; 39(1): 50-61.

19. Ding YH, Mrizek M, Lai Q, Wu Y, Reyes Jr R, Li $\mathrm{J}$, et al. Exercise preconditioning reduces brain damage and inhibits TNF-alpha receptor expression after hypoxia/reoxygenation: an in vivo and in vitro study. Curr Neurovasc Res. 2006; 3(4): 263.

20. Ding YH, Young CN, Luan X, Li J, Rafols JA, Clark JC, et al. Exercise preconditioning ameliorates inflammatory injury in ischemic rats during reperfusion .Acta Neuropathol. 2005; 109(3): 237-46.

21. Chen YW, Chen SH, Chou W, Lo YM, Hung CH, Lin MT. Exercise pretraining protects against cerebral ischaemia induced by heat stroke in rats. $\mathrm{Br} \mathrm{J}$ Sports 
Med. 2007; 41(9): 597-602.

22. Del Zoppo GJ. The neurovascular unit in the setting of stroke. J Intern Med. 2010; 267(2): 156-71.

23. Kochanski R, Dornbos III D, Ding Y. Neuroprotection and Physical Preconditioning: Exercise, Hypothermia, and Hyperthermia. Innate Tolerance in the CNS: Springer; 2013. p. 105-31.

24. Wang X, Zhang M, Feng R, Li WB, Ren SQ, Zhang $\mathrm{J}$, et al. Physical exercise training and neurovascular unit in ischemic stroke. Neuroscience. 2014; 271: 99-107.

25. Dornbos III D, Ding Y. Mechanisms of Neuroprotection Underlying Physical Exercise in Ischemia-Reperfusion Injury. InTech. 2012; p. 299-326.

26. Del Zoppo GJ, Mabuchi T. Cerebral microvessel responses to focal ischemia. J Cereb Blood Flow Metab. 2003; 23(8): 879-94.

27. Ding Y, Li J, Yao W, Rafols J, Clark J, Ding Y. Exercise preconditioning upregulates cerebral integrins and enhances cerebrovascular integrity in ischemic rats. Acta Neuropathol. 2006; 13(1): 174-84.

28. Lo EH, Dalkara T, Moskowitz MA. Mechanisms, challenges and opportunities in stroke. Nat Rev Neurosci. 2003; 4(5): 399-414.

29. Zhang F, Wu Y, Jia J. Exercise preconditioning and brain ischemic tolerance. Neuroscience. 2011; 177: 170-76.

30. Ding Y, Li J, Luan X, Ding YH, Lai Q, Rafols $\mathrm{J}$, et al. Exercise pre-conditioning reduces brain damage in ischemic rats that may be associated with regional angiogenesis and cellular overexpression of neurotrophin. Neuroscience. 2004; 124(3): 583-591.

31. Bullitt E, Rahman F, Smith J, Kim E, Zeng D, Katz L, et al. The effect of exercise on the cerebral vasculature of healthy aged subjects as visualized by MR angiography. Am J Neuroradiol. 2009; 30(10): 1857-63.

32. Ding YH, Luan XD, Li J, Rafols JA, Guthinkonda M, Diaz FG, et al. Exercise-induced overexpression of angiogenic factors and reduction of ischemia/ reperfusion injury in stroke. Curr Neurovascu Res. 2004; 1(5): 411-20.

33. Hu X, Zheng H, Yan T, Pan S, Fang J, Jiang R, et al. Physical exercise induces expression of CD31 and facilitates neural function recovery in rats with focal cerebral infarction. Neurol Res. 2010; 32(4): 397-402.

34. Li J, Ding YH, Rafols JA, Lai Q, McAllister Ii JP, Ding Y. Increased astrocyte proliferation in rats after running exercise. Neurosci Lett. 2005; 386(3): 160-4.

35. Lee SU, Kim DY, Park SH, Choi DH, Park HW, Han TR. Mild to moderate early exercise promotes recovery from cerebral ischemia in rats. Can J Neurol Sci. 2009; 36(4): 443-9.

36. Ogoh S, Ainslie PN. Cerebral blood flow during exercise: mechanisms of regulation. J Appl Physiol. 2009; 107(5): 1370-80.

37. Querido JS, Sheel AW. Regulation of cerebral blood flow during exercise. Sports Med (Auckland, NZ). 2007; 37(9): 765-82.

38. Kinni H, Guo M, Ding JY, Konakondla S, Dornbos Iii D, Tran R, et al. Cerebral metabolism after forced or voluntary physical exercise. Brain Res. 2011; 1388: 48-55.

39. Minchenko O, Opentanova I, Caro J. Hypoxic regulation of the 6-phosphofructo-2-kinase/fructose-2, 6-bisphosphatase gene family (PFKFB-1-4) expression in vivo. FEBS Lett. 2003; 554(3): 264-70.

40. Kahn BB, Alquier T, Carling D, Hardie DG. AMPactivated protein kinase: ancient energy gauge provides clues to modern understanding of metabolism. Cell Metab. 2005; 1(1): 15-25.

41. Aschenbach WG, Sakamoto K, Goodyear LJ. 5 'adenosine monophosphate-activated protein kinase, metabolism and exercise. Sports Med. 2004; 34(2): 91-103.

42. Dornbos D, Zwagerman N, Guo M, Ding JY, Peng C, Esmail F, et al. Preischemic exercise reduces brain damage by ameliorating metabolic disorder in ischemia/reperfusion injury. J Neurosci Res. 2013; 91(6): 818-27.

43. Maurer MH, Geomor HK, Bürgers HF, Schelshorn DW, Kuschinsky W. Adult neural stem cells express glucose transporters GLUT1 and GLUT3 and regulate GLUT3 expression. FEBS Lett. 2006; 580(18): 4430-4.

44. Semenza GL, Agani F, Booth G, Forsythe J, Iyer $\mathrm{N}$, Jiang $\mathrm{BH}$, et al. Structural and functional analysis 


\section{$\approx$}

of hypoxia-inducible factor 1. Kidney Int. 1997; 51(2): 553-5.

45. Hardie DG, Scott JW, Pan DA, Hudson ER. Management of cellular energy by the AMPactivated protein kinase system. FEBS Lett. 2003; 546(1): 113-20.

46. Deister C, Schmidt CE. Optimizing neurotrophic factor combinations for neurite outgrowth. J Neural Eng. 2006; 3(2): 172-9.

47. Cohen-Cory S, Kidane AH, Shirkey NJ, Marshak S. Brain-derived neurotrophic factor and the development of structural neuronal connectivity. Dev Neurobiol. 2010; 70(5): 271-88.

48. Shahbazi M, Shayan A, Samadi A, Nemati Z. The effect of resistance exercise on memory and neurotrophic factor levels in sedentary student. JMLD. 2015: (in press).

49. Shahbazi M, Samadi A, Nemati Z, Shayan A. The effect of endurance exercise on attention and brain derived neurotrophic factor levels in sedentary men and women. Modern Olympic. 2015: (in press).

50. Zoladz JA, Pilc A. The effect of physical activity on the brain derived neurotrophic factor: from animal to human studies. J Physiol Pharmacol. 2010; 61(5): $533-41$.

51. Ickes BR, Pham TM, Sanders LA, Albeck DS, Mohammed AH, Granholm AC. Long-term environmental enrichment leads to regional increases in neurotrophin levels in rat brain. Exp Neurol. 2000; 164(1): 45-52.

52. Neeper SA, Gómez-Pinilla F, Choi J, Cotman CW. Physical activity increases mRNA for brain-derived neurotrophic factor and nerve growth factor in rat brain. Brain Res. 1996; 726(1): 49-56.

53. Schäbitz WR, Schwab S, Spranger M, Hacke W. Intraventricular brain-derived neurotrophic factor size after focal cerebral ischemia in rats. J Cereb Blood Flow Metab. 1997; 17(5): 500-6.

54. Schäbitz WR, Steigleder T, Cooper-Kuhn CM, Schwab S, Sommer C, Schneider A, et al. Intravenous brain-derived neurotrophic factor enhances poststroke sensorimotor recovery and stimulates neurogenesis. Stroke. 2007; 38(7): 2165-72.

55. Ang E, Wong P, Moochhala S, Ng Y. Neuroprotection associated with running: is it a result of increased endogenous neurotrophic factors? Neuroscience. 2003; 118(2): 335-45.

56. Obrenovitch TP. Molecular physiology of preconditioning-induced brain tolerance to ischemia. Physiol Rev. 2008; 88(1): 211-47.

57. Garcia-Bonilla L, Benakis C, Moore J, Iadecola C, Anrather J. Immune mechanisms in cerebral ischemic tolerance. Front Neurosci. 2014; 8: 44.doi: 10.3389/ fnins. 2014. 00044.

58. Zwagerman N, Plumlee C, Guthikonda M, Ding Y. Toll-like receptor- 4 and cytokine cascade in stroke after exercise. Neurol Res. 2010; 32(2): 123-6.

59. Rothwell NJ, Hopkins SJ. Cytokines and the nervous system II: actions and mechanisms of action. Trends Neurosci. 1995; 18(3): 130-6.

60. Cárdenas A, Moro MA, Leza JC, O’Shea E, Dávalos A, Castillo J, et al. Upregulation of TACE/ADAM17 after ischemic preconditioning is involved in brain tolerance. J Cereb Blood Flow Metab 2002 ; 22(11): 1297-32.

61. Reyes Jr R, Wu Y, Lai Q, Mrizek M, Berger J, Jimenez DF, et al. Early inflammatory response in rat brain after peripheral thermal injury. Neurosci Lett. 2006; 407(1): 11-5.

62. Won MH, Kang TC, Jeon GS, Lee JC, Kim DY, Choi EM, et al. Immunohistochemical detection of oxidative DNA damage induced by ischemia-reperfusion insults in gerbil hippocampus in vivo. Brain Res. 1999; 836(1): 70-8.

63. Hamakawa M, Ishida A, Tamakoshi K, Shimada H, Nakashima H, Noguchi T, et al. Repeated short-term daily exercise ameliorates oxidative cerebral damage and the resultant motor dysfunction after transient ischemia in rats. J Clin Biochem Nutr. 2013; 53(1): 8-14.

64. Perez-Pinzon MA, Dave KR, Raval AP. Role of reactive oxygen species and protein kinase $\mathrm{C}$ in ischemic tolerance in the brain. Antioxid Redox Signal. 2005; 7(9-10): 1150-7.

65. Camiletti-Moirón D, Aparicio V, Aranda P, Radak Z. Does exercise reduce brain oxidative stress? A systematic review. Scand J Med Sci Sports. 2013; 23(4): e202-12.

66. Cechetti F, Worm PV, Elsner VR, Bertoldi K, 
Sanches E, Ben J, et al. Forced treadmill exercise prevents oxidative stress and memory deficits following chronic cerebral hypoperfusion in the rat. Neurobiol Learn Mem. 2012; 97(1): 90-6.

67. Laufs U, Werner N, Link A, Endres M, Wassmann $\mathrm{S}$, Jürgens $\mathrm{K}$, et al. Physical training increases endothelial progenitor cells, inhibits neointima formation, and enhances angiogenesis. Circulation. 2004; 109(2): 220-6.

68. El Idrissi A, Trenkner E. Growth factors and taurine protect against excitotoxicity by stabilizing calcium homeostasis and energy metabolism. J Neurosci. 1999; 19(21): 9459-68.

69. Lazou A, Iliodromitis E, Cieslak D, Voskarides K, Mousikos S, Bofilis E, et al. Ischemic but not mechanical preconditioning attenuates ischemia/reperfusion induced myocardial apoptosis in anaesthetized rabbits: the role of Bcl-2 family proteins and ERK1/2. Apoptosis. 2006; 11(12): 2195-204.

70. Voegeli T, Wintink A, Currie RW. Heat Shock Proteins Hsp70 and Hsp27 and Neural Cellular Protection. In: Asea AA, Brown I, editors. Heat Shock Proteins and the Brain: Implications for Neurodegenerative Diseases and Neuroprotection. Heat Shock Proteins. 3: Springer Netherlands; 2008; p. 159-77.

71. Ouyang YB, Xu LJ, Sun YJ, Giffard RG. Overexpression of inducible heat shock protein 70 and its mutants in astrocytes is associated with maintenance of mitochondrial physiology during glucose deprivation stress. Cell Stress Chaperones. 2006; 11(2): 180-6.

72. Masada T, Hua Y, Xi G, Ennis SR, Keep RF. Attenuation of ischemic brain edema and cerebrovascular injury after ischemic preconditioning in the rat. J Cereb Blood Flow Metab. 2001; 21(1): 22-33.

73. Hayes K, Sprague S, Guo M, Davis W, Friedman A, Kumar A, et al. Forced, not voluntary, exercise effectively induces neuroprotection in stroke. Acta Neuropathol. 2008; 115(3): 289-96.

74. Goel G, Guo M, Ding J, Dornbos III D, Ali A, Shenaq M, et al. Combined effect of tumor necrosis factor (TNF)- $\alpha$ and heat shock protein (HSP)-70 in reducing apoptotic injury in hypoxia: A cell culture study. Neurosci Lett. 2010; 483(3): 162-6.

75. Zhuang S, Schnellmann RG. A death-promoting role for extracellular signal-regulated kinase. J Pharmacol Exp Ther. 2006; 319(3): 991-7.
76. Zhang F, Wu Y, Jia J, Hu YS. Pre-ischemic treadmill training induces tolerance to brain ischemia: involvement of glutamate and ERK1/2. Molecules. 2010; 15(8): 5246-57.

77. Zhang L, Niu W, He Z, Zhang Q, Wu Y, Jiang C, et al. Autophagy suppression by exercise pretreatment and p38 inhibition is neuroprotective in cerebral ischemia. Brain Res. 2014; 1587: 127-32.

78. Sattler R, Tymianski M. Molecular mechanisms of glutamate receptor-mediated excitotoxic neuronal cell death. Mol Neurobiol. 2001; 24(1-3): 107-29.

79. Meldrum BS. Glutamate as a neurotransmitter in the brain: review of physiology and pathology. J Nutr. 2000; 130(4S Suppl): 1007S-15S.

80. Dirnagl U, Becker K, Meisel A. Preconditioning and tolerance against cerebral ischaemia: from experimental strategies to clinical use. Lancet Neurol. 2009; 8(4): 398-412.

81. Sommer C, Roth S, Kuhn R, Kiessling M. Metabotropic glutamate receptor subtypes are differentially expressed after transient cerebral ischemia without, during and after tolerance induction in the gerbil hippocampus. Brain Res. 2000; 872(1): 172-80.

82. Zhang F, Jia J, Wu Y, Hu Y, Wang Y. The effect of treadmill training pre-exercise on glutamate receptor expression in rats after cerebral ischemia. Int J Mol Sci. 2010; 11(7): 2658-69.

83. Yang $\mathrm{X}$, He Z, Zhang Q, Wu Y, Hu Y, Wang X, et al. Pre-Ischemic Treadmill Training for Prevention of Ischemic Brain Injury via Regulation of Glutamate and Its Transporter GLT-1. Int J Mol Sci. 2012; 13(8): 9447-59.

84. Beal MF. Mitochondria take center stage in aging and neurodegeneration. Ann Neurol. 2005; 58(4): 495-505.

85. Marques-Aleixo I, Oliveira PJ, Moreira PI, Magalhães J, Ascensão A. Physical exercise as a possible strategy for brain protection: Evidence from mitochondrial-mediated mechanisms. Prog Neurobiol. 2012; 99(2): 149-62.

86. Steiner JL, Murphy EA, McClellan JL, Carmichael MD, Davis JM. Exercise training increases mitochondrial biogenesis in the brain. J Appl Physiol. 2011; 111(4): 1066-71. 
87. Bayod S, Del Valle J, Canudas AM, Lalanza JF, Sanchez-Roigé S, Camins A, et al. Long-term treadmill exercise induces neuroprotective molecular changes in rat brain. J Appl Physiol. 2011; 111(5): 1380-90.

88. Ding Q, Vaynman S, Souda P, Whitelegge JP, Gomez-Pinilla F. Exercise affects energy metabolism and neural plasticity-related proteins in the hippocampus as revealed by proteomic analysis. Eur J Neurosci. 2006;
24(5): 1265-76.

89. Kirchner L, Chen WQ, Afjehi-Sadat L, Viidik A, Skalicky M, Höger H, et al. Hippocampal metabolic proteins are modulated in voluntary and treadmill exercise rats. Exp Neurol. 2008; 212(1): 145-51.

90. Belca M. Effects of physical activity in brain mitochondrial function. $\mathrm{PhD}$ Thesis. Faculty of Sports University of Porto. 2013. 